\title{
La contribución inicial de la jurisdicción contencioso-administrativa a la construcción del régimen de control a posteriori (comunicación previa y declaración responsable)*
}

\author{
Marida Rodríguez Font
}

Doctora en Derecho Universidad de Barcelona

\begin{abstract}
SUMARIO: I.- INTRODUCGIÓN. II.- LA OPORTUNIDAD DEL MANTENIMIENTO DEL RÉGIMEN AUTORIZATORIO O SU SUSTITUCIÓN POR LOS REGÍMENES DE COMUNICACIÓN PREVIA Y DECLARACIÓN RESPONSABLE. III.- LA APLICACIÓN EXTENSIVA DEL RÉGIMEN JURÍDICO DE LA DECLARACIÓN RESPONSABLE Y LA COMUNICACIÓN PREVIA AL CONTEXTO DE ACTIVIDADES INICIADAS SIN LA OBLIGATORIA LICENCIA. IV.EL SOMETIMIENTO DE LA ADMINISTRACIÓN PÚBLICA AL DEBER DE COMUNICACIÓN PREVIA. V.- LA DESAPARICIÓN DE ILÍCITOS ADMINISTRATIVOS COMO CONSEGUENGIA DE LA REFORMA DE GIERTOS REGÍMENES SANGIONADORES. VI.- LA SUBSANACIÓN DE LAS DECLARACIONES RESPONSABLES Y LAS GONSEGUENGIAS DE LA OMISIÓN DE DATOS DE GARÁGTER ESENGIAL. VII.- CONCLUSIONES.
\end{abstract}

\section{INTRODUGGIÓN}

Muchos son, a día de hoy, los textos doctrinales existentes en torno al cambio de eje vertebrador de la intervención pública sobre las actividades de los particulares. Se echa de menos, sin embargo, un análisis de las decisiones de los tribu-

* Comentario elaborado en el marco del Proyecto de investigación "Análisis de costes y beneficios en el Derecho público: métodos e instrumentos para la mejora de la regulación" (DER201231112) y en el Proyecto de investigación "Estrategias reguladoras y de aplicación del Derecho público más allá del aparato público del Estado” (DER2012-39449). 
nales españoles sobre la aplicación y contenidos de ciertas normas -del Estado, de las Comunidades Autónomas e incluso de las Administraciones locales- que han resultado modificadas en pro de su imperativa adaptación a los nuevos postulados de la Directiva de servicios y de las leyes de transposición ${ }^{1}$. Nos referimos a disposiciones que plantean diferentes escenarios y controversias a cuyo esclarecimiento y resolución ha contribuido, tímidamente, el orden jurisdiccional contencioso-administrativo.

El objeto de este trabajo es un comentario de las sentencias existentes ${ }^{2}$. Si bien se inaugura con las decisiones del Tribunal Supremo, se ha considerado de interés, asimismo, comentar todas aquellas que puedan aportar rédito a la cuestión que hoy nos ocupa. Se presenta, así, una crónica de todas las resoluciones dictadas hasta el momento -sin discriminación en función del órgano judicial conocedor-, centrándonos en exclusiva en los aspectos relacionados directa o indirectamente con las figuras de la declaración responsable y la comunicación previa; obviando, por lo tanto, otros extremos que, aun siendo de interés, escapan a este cometido.

Pueden agruparse en cinco las materias sobre las que han tenido oportunidad de manifestarse tanto el Tribunal Supremo, la Audiencia Nacional, como los Tribunales Superiores de Justicia de las Comunidades Autónomas.

La oportunidad del mantenimiento del régimen autorizatorio previsto en dis-

${ }^{1}$ Directiva 2006/123/CE del Parlamento Europeo y del Consejo, de 12 de diciembre de 2006, relativa a los servicios en el mercado interior (en adelante, Directiva de servicios); Ley 17/2009, de 23 de noviembre, sobre libre acceso a las actividades de servicios y su ejercicio y Ley 25/2009, de 22 de diciembre, de modificación de diversas leyes para su adaptación a la Ley sobre el libre acceso a las actividades de servicios y su ejercicio.

${ }^{2}$ Este comentario da continuidad a una línea propia de investigación que, iniciada en el año 2003 -con la publicación del libro Régimen de comunicación e intervención ambiental. Entre la simplificación administrativa y la autorregulación, Atelier, Barcelona- me ha dado la oportunidad de estudiar el régimen jurídico aplicable a las instituciones de la comunicación previa y declaración responsable desde distintas perspectivas. Entre otros, pueden citarse "Declaración responsable y comunicación previa: su operatividad en el ámbito local”, Anuario del Gobierno Local núm. 1, 2009, págs. 261-300; “Técnicas de control en la transposición de la Directiva de Servicios: comunicación previa y declaración responsable", en La termita Bolkestein: mercado único vs. derechos ciudadanos. ARIAS MARTÍNEZ, M. A; ALMEIDA CERREDA, M, y NOGUEIRA LÓPEZ, A., (Dirs.), Civitas, Madrid, 2012, págs. 81-98; y "La intervención administrativa en las actividades de baja incidencia en el entorno: complejidad y evolución de la técnica en la comunicación ambiental", en Libre mercado y protección ambiental: intervención y orientación ambiental de las actividades económicas, SANZ LARRUGA, F. J; GARCÍA PÉREZ, M., PERNAS GARCÍA, J. J y RODRÍGUEZ-ARANA MUÑOZ, J., (Dirs.), INAP, 2013, págs. 107-141. 
tintas disposiciones de naturaleza reglamentaria o su sustitución por los regímenes de comunicación previa y declaración responsable ha sido el único debate en el contexto del cual se ha pronunciado el Alto Tribunal. Con estas sentencias se dará comienzo el análisis jurisprudencial.

En segundo lugar nos referiremos a unas sentencias, la mayoría de ellas del Tribunal Superior de Justicia de Madrid, en las que las disposiciones reguladoras de la declaración responsable y la comunicación previa (tanto las de la Ley 30/1992, de 26 de noviembre, como las de la Ley 7/1985, de 2 de abril) sirven al órgano jurisdiccional de argumento denegatorio de ciertas medidas cautelares. Se trata, por lo menos a primera vista, de una suerte de aplicación extensiva del régimen de estos institutos al contexto de actividades iniciadas sin la obligatoria licencia; en una utilización un tanto rebuscada, desde nuestro punto de vista, de su parco régimen legal. Los órganos judiciales, sin embargo, realizan en este contexto afirmaciones con efecto directo sobre los institutos objeto de atención y que merecen, por ello, ser destacadas.

En tercer lugar comentaremos una sentencia de la Audiencia Nacional que, a pesar de situarse fuera de los márgenes temporales de la normativa de transposición de la Directiva de servicios, tiene cierto interés por cuanto prescribe la sumisión de la Administración pública -en este caso de una entidad local-, al régimen de la comunicación previa al que quedan sujetos los particulares.

En cuarto lugar nos vamos a detener en una controversia sumamente interesante a la que las resoluciones del Tribunal Superior de Justicia de Canarias (fundamentalmente) han dado visibilidad: la desaparición de ilícitos administrativos como consecuencia de la reforma de ciertos regímenes sancionadores. Con la sustitución del control previo de la Administración por el control a posteriori desaparece, en algunos casos, la concreta infracción de ejercicio de actividades sin la preceptiva licencia. Así, los Tribunales se han visto obligados a dictaminar, entre otros, sobre la posibilidad de aplicación del principio de retroactividad de disposiciones sancionadoras posteriores y favorables; donde el régimen autorizatorio ha resultado sustituido por el de la comunicación previa o declaración responsable. Afloran, en este último apartado, cuestiones de no poca enjundia jurídica que dejaremos aquí meramente apuntadas y que serán objeto, en sí mismas, de otro trabajo.

Cerrará esta crónica un comentario sobre una sentencia de finales de 2013 del Tribunal Superior de Justicia de Andalucía. La singularidad de esta resolución estriba en los aspectos del régimen jurídico y procedimental de la declaración responsable que en mayor o menor medida aborda; en un meritorio intento de dar respuesta a algunas de sus más acuciantes incógnitas. 


\section{LA OPORTUNIDAD DEL MANTENIMIENTO DEL RÉGI- MEN AUTORIZATORIO O SU SUSTITUGIÓN POR LOS REGÍMENES DE COMUNICACIÓN PREVIA Y DECLARA- CIÓN RESPONSABLE}

El Tribunal Supremo se ha manifestado, hasta hoy, en cuatro ocasiones sobre temas relacionados con la temática que nos ocupa; siendo la primera resolución de mediados del año 2011 y la última de principios de $2012^{3}$.

Estas sentencias tienen en común, como decíamos, la discusión sobre la oportunidad o no de mantener el régimen autorizatorio para concretos tipos de actividades y servicios afectados por la Directiva de servicios, y la normativa nacional de transposición, tanto Estatal como autonómica ${ }^{4}$.

Siguiendo un orden cronológico, la sentencia de 29 de junio de 2011 (núm. rec. 252/2010) resuelve el recurso contencioso-administrativo planteado por el Consejo General de Ingenieros Industriales contra el Real Decreto 338/2010, de 19 de marzo, por el que se modifica el Reglamento de la Infraestructura para la calidad y seguridad industrial.

En la segunda parte de la demanda presentada por el Consejo General de Ingenieros Industriales éste alega, entre otros, la incompatibilidad de la sumisión de los organismos de control a un sistema de autorización previa, considerando dicho sometimiento contrario a la Ley 17/2009, de 23 de noviembre, sobre libre acceso a las actividades de servicio y su ejercicio ${ }^{5}$ y al artículo 71 bis de la Ley 30/1992; en la medida que no queda justificado por una razón imperiosa de interés general y contradice el principio de proporcionalidad.

${ }^{3}$ Sentencia del Tribunal Supremo de 29 de junio de 2011 (núm. rec. 252/2010); Sentencia del Tribunal Supremo de 7 de octubre de 2011 (núm. rec. 410/2010); Sentencia del Tribunal Supremo de 13 de febrero de 2012 (núm. rec. 239/2010) y Sentencia del Tribunal Supremo de 27 de febrero de 2012 (núm. rec. 191/2010).

${ }^{4}$ Sobre este tema véanse, entre otros, La termita Bolkestein: mercado único vs. derechos ciudadanos. ARIAS MARTÍNEZ, M. A; ALMEIDA CERECEDA, M, y NOGUEIRA LÓPEZ, A., (Dirs.), Civitas, Madrid, 2012; El impacto de la Directiva de servicios en las administraciones públicas: aspectos generales y sectoriales, AGUADO CUDOLÀ, V. y NOGUERA DE LA MUELA, B. (Dirs.), Atelier, Barcelona, 2012; Libre mercado y protección ambiental: intervención y orientación ambiental de las actividades económicas, SANZ LARRUGA, F. J., GARCÍA PÉREZ, M., PERNAS GARCIIA, J. J. y RODRÍGUEZ-ARANA MUÑOZ, J., (Dirs.), INAP, 2013; y Simplificación del procedimiento administrativo y mejora de la regulación, GAMERO CASADO (Coord.), Tirant lo blanc, Valencia, 2014.

${ }^{5}$ Arts. 9, 10 y 12.2 d). 
El Tribunal Supremo, tras repasar el contenido de los artículos de la Ley paraguas que acabamos de mencionar, toma como punto de partida para justificar su posterior decisión la reforma de la Ley de industria que operó la Ley 25/2009, de 22 de diciembre, de modificación de diversas Leyes para su adaptación a la Ley sobre el libre acceso a las actividades de servicios y su ejercicio.

Tras reconocer el argumento del Abogado del Estado -esto es, que la Ley ómnibus había mantenido, al reformar el artículo 15 de la Ley de industria, la necesidad de autorización para los organismos de control-, realiza un análisis que va más allá de concretos preceptos. Así, recuerda a las partes, que también resultó modificado el artículo 4 de la Ley de industria dedicado a la libertad de establecimiento; artículo que no hace sino reconocer la libertad de establecimiento para la instalación, ampliación y traslado de las actividades industriales, sometiéndolas a un régimen de comunicación o declaración responsable de los interesados. Especial énfasis se pone en el último apartado del precepto, que prevé que únicamente pueda requerirse autorización administrativa previa cuando resulte obligado para el cumplimiento de obligaciones del Estado derivadas de la normativa comunitaria o de los Tratados y convenios internacionales.

De este modo, el Tribunal entiende que el carácter general de este precepto obliga, a partir de la entrada en vigor de la reforma, a interpretar el resto de la Ley de industria a la luz del mismo. Tanto el apartado 5 del artículo 4 de esta última Ley, como la interpretación que se desprende de la Directiva de servicios y de las Leyes paraguas y ómnibus (sobre cuando es posible supeditar el acceso de una actividad de servicios a un régimen autorizatorio), le llevan a la confirmar que si el Estado español pretende establecer este régimen, o bien debe justificarlo en la concurrencia de una razón imperiosa de interés general -motivación que puede hallarse en una Ley o, en su defecto y siempre que la correspondiente ley sectorial lo admita, en un reglamento- o en el cumplimiento de sus obligaciones comunitarias o internacionales ${ }^{6}$.

\footnotetext{
${ }^{6}$ Sobre el principio de libertad de establecimiento y el llamado "efecto de la interpretación conforme", véase la sentencia del Tribunal Superior de Justicia de Cantabria, núm. 305/2012, de 13 de abril de 2012. En este caso, el Tribunal conoce en apelación sobre una sentencia que dio la razón a dos terceros recurrentes que impugnaron la resolución desfavorable de un recurso de reposición interpuesto, contra una decisión de concesión de licencia de actividad (salón de belleza) a otro particular; que fue, en consecuencia, anulada.

Entiende el Tribunal que la invocada inocuidad de la actividad era tal y que la misma no se encontraba incluida en el anexo de las actividades que requieren licencia de actividad, por no exigirse en la normativa medioambiental autonómica. Observa, seguidamente, que en la fecha de otorgamiento de la licencia (enero 2009) estaba vigente todavía lo dispuesto en el artículo 22 del De-
} 
En opinión del Alto Tribunal, ni el artículo 15 de la Ley de Industria, ni el artículo 43 del Reglamento modificado por el Real Decreto objeto de impugnación acometen en momento alguno dicha justificación limitándose, sólo, a prever la regla general de necesidad de autorización. Concluye, entonces, declarando inaplicables ambos preceptos; o lo que es lo mismo, proclamando la no necesidad de autorización administrativa para los organismos de control salvo que por Ley o reglamento se justifique la misma: "en defecto de autorización, y al margen de la obligatoriedad de acreditación, los organismos de control quedarían en cambio obligados a efectuar la comunicación o declaración responsable prevista en el artículo 4 de la Ley de Industria"7.

creto de 17 de junio de 1955 por el que se aprueba el Reglamento de Servicios de las Corporaciones Locales (la licencia de apertura de establecimientos industriales y mercantiles). Tras este reconocimiento, comienza su discurso sobre la "drástica modificación" que ha sufrido el régimen de estos establecimientos a raíz de la Directiva de servicios. Tras un exhaustivo repaso a la normativa posterior a la misma y unas interesantes reflexiones sobre "las distorsiones en el funcionamiento de los mercados de servicios" da contenido, y esto es lo más destacable de esta sentencia, a lo que denomina el "efecto de la interpretación conforme" (fundamento jurídico 2): "En esta tesitura, no resulta irrazonable la interpretación llevada a cabo por el Ayuntamiento, precisamente respetando los principios de una Directiva que, si bien no transpuesta, si generaba el efecto de interpretación conforme de la normativa interna para que desplegara sus efectos, máxime cuando cabe desistir a la petición de licencia y someterse al nuevo régimen derivado de la Directiva que elude este control previo salvo en los supuestos tasados y con los requisitos puestos de manifiesto. Todo ello partiendo del principio de libertad de establecimiento que inspira la Directiva comunitaria y considerando a la licencia cuestionada como una restricción a dicha libertad, como indica el propio preámbulo de nuestra Ley de transposición". Termina así el Tribunal estimando el recurso interpuesto y revocando el previo pronunciamiento.

${ }^{7}$ Fundamento jurídico cuarto. Esta sentencia del Tribunal Supremo sirve como fundamento de la resolución del Tribunal Superior de Justicia de Castilla-La Mancha núm. 685/2013, de 23 de diciembre de 2013. En este caso, el Consejo General de Colegios Oficiales de Peritos e Ingenieros Técnicos industriales y el Consejo de Colegios Profesionales de Ingenieros Técnicos industriales de Castilla La Mancha interpusieron recurso contencioso-administrativo contra el Decreto 6/2011 de 1 de febrero, por el que se regulan las actuaciones en materia de certificación energética de edificios en la Comunidad de Castilla-La Mancha y se crea el Registro autonómico de certificados de eficiencia Energética y entidades de verificación de conformidad. Pretendían, entre otros, la nulidad de los preceptos que exigían una autorización a las entidades de verificación. El TSJ recuerda que la necesidad de autorización administrativa de los organismos de control fue declarada contraria a Derecho en la STS de 29 de julio de 2011 y concluye que el Decreto impugnado no se ajustaba al mismo en cuanto sometía a autorización previa la consideración de entidad de verificación "pues en absoluto aparece justificación de la concurrencia de una razón imperiosa de interés general o que resultara obligado para el cumplimiento de obligaciones comunitarias o internacionales la autorización administrativa o "acreditación" previas litigiosas". Fundamento jurídico quinto. 
La declaración de nulidad de los preceptos controvertidos se haría por este Tribunal más tarde, en la sentencia de 27 de febrero de 2012 (núm. rec. 191/2010).

El Consejo General de Colegios Oficiales de Peritos e Ingenieros Técnicos Industriales presentó recurso contencioso contra el mismo Real Decreto, por considerar que las condiciones que establecía -incluyendo la exigencia de autorización-, no podían entenderse aplicables a los organismos de control que fueran personas físicas; en la medida que fijaban una serie de requisitos de imposible cumplimiento por estos, que impedían u obstaculizaban su actividad.

El Tribunal Supremo reiteró los argumentos ya esgrimidos en ocasión del proceso que acabamos de comentar y, tras desestimar parte de la pretensión inicial del Consejo de Peritos e Ingenieros (en la que no nos detendremos aquí), acogió la pretensión de declarar nulos los preceptos del Reglamento de la Infraestructura para la calidad y seguridad industrial. La razón de ello fue, a juicio del Tribunal, la falta de adecuación de dichos artículos a las normas de rango superior que sólo permiten someter a autorización administrativa la actividades de servicios respecto las que queden cumplidamente demostradas las razones imperiosas de interés general ${ }^{8}$.

Otro recurso contencioso administrativo presentado por el Consejo General de Colegios Oficiales de Peritos e Ingenieros Técnicos Industriales contra distinta disposición reglamentaria estatal, dio lugar a la decisión del Tribunal Supremo que comentaremos ahora: la sentencia de 7 de octubre de 2011 (núm. rec. 410/2010), en la que el Alto Tribunal se manifiesta sobre la pertinencia de someter ciertas actividades al régimen de declaración responsable.

En esta ocasión, se interpuso demanda contenciosa contra el Real Decreto $795 / 2010$, de 16 de junio, por el que se regula la comercialización y manipulación de gases fluorados y equipos basados en los mismos, así como la certificación de los profesionales que los utilizan. Se pretendía la nulidad de todo el Real Decreto por defecto esencial en su procedimiento de elaboración; siendo, no obstante, la causa de impugnación que interesa a efectos de este estudio, la objeción al régimen de certificación que dicha norma establecía y la solicitud de nulidad del mismo.

El Consejo de Peritos e Ingenieros entendió que no existía justificación legal para la exigencia, a los profesionales, del requisito de habilitarlos para llevar a ca-

\footnotetext{
${ }^{8}$ Fundamento jurídico quinto.
} 
bo las actividades que contemplaba la disposición; cuyo núcleo esencial de la regulación era, precisamente, este. La imposición de una acreditación previa se valoró contraria a la libertad de establecimiento consagrada en el artículo 4 de la Ley 17/2009, de 23 de noviembre, sobre el libre acceso a las actividades de servicios y su ejercicio, así como al principio de intervención mínima del artículo 3.9 que sólo exigiría el sometimiento a una declaración responsable.

El Tribunal Supremo, sin embargo, desestimó este motivo de impugnación. El fundamento de dicha decisión fue que el Real Decreto 795/2010, de 16 de junio, contenía disposiciones dictadas en ejercicio de una habilitación expresa de distintos Reglamentos comunitarios; cuyos preceptos el órgano se detiene a referenciar. Esta habilitación expresa por normas comunitarias se entendió que excluía necesariamente la aplicabilidad de las disposiciones legales estatales invocadas por los demandantes, pues daban cobertura inequívoca a la exigencia de una certificación ${ }^{9}$.

Vemos entonces como en esta ocasión el Alto Tribunal encuentra en la normativa europea la justificación directa del mantenimiento del régimen autorizatorio. Justificación, a su parecer, inexistente en el primer caso expuesto, en el que su necesidad no derivaba de normas comunitarias de aplicación preferente ni de normas estatales; pues no argumentaban, estas últimas, debidamente su persistencia ${ }^{10}$.

La última de las decisiones que comentaremos en las que el Tribunal Supremo ha tenido la oportunidad de tratar el régimen de intervención aplicable a las actividades de servicios ha sido la sentencia de 13 de febrero de 2012 (núm. rec. 239/2010). Este es un caso particular, por cuanto a pesar de no discutirse en sí el sistema autorizatorio establecido (sino ciertas particularidades del mismo), el ór-

${ }^{9}$ Así, llegó a la conclusión que "la misma Ley 17/2009, de 23 de noviembre, conectada también con el Derecho de la Unión Europea que transpone, soslaya de forma expresa -si necesario fuera- cualquier posibilidad de conflicto con las normas de aplicación prevalente que se acaban de indicar al disponer, en su artículo 2.4, que en caso de conflicto entre las disposiciones de dicha Ley y otras disposiciones que regulen el acceso a una determinada actividad de servicios o su ejercicio en aplicación de la normativa comunitaria, deben prevalecer estas últimas en aquellos aspectos expresamente previstos en la normativa comunitaria de la que traigan causa, precaución que se reitera en el artículo 4.3 de la misma". Fundamento jurídico tercero.

${ }^{10}$ ESTEVE PARDO, J., "La deconstrucción y previsible recomposición del modelo de autorización administrativa", en La termita Bolkestein: mercado único vs. derechos ciudadanos, ARIAS MARTÍNEZ, M. A; ALMEIDA CERREDA, M, y NOGUEIRA LÓPEZ, A., (Dirs.), Givitas, Madrid, 2012, págs. 29-42. 
gano jurisdiccional no desperdicia la ocasión para valorar la conveniencia del mismo.

La Federación Estatal de Enseñanza de Comisiones Obreras interpuso recurso contencioso-administrativo contra el Real Decreto 369/2010, de 26 de marzo, por el que se modifica el Reglamento de las escuelas particulares de conductores y el Real Decreto 2100/1976, de 10 de agosto, sobre fabricación, importación, venta y utilización de piezas, elementos o conjuntos para reparación de automóviles, para adaptar su contenido a la Ley 17/2009 y 25/2009; paraguas y ómnibus respectivamente.

Entre las pretensiones esgrimidas en la demanda estaba la de la nulidad de determinados preceptos referidos a la exigencia de nuevas autorizaciones administrativas cada vez que el profesor inicia una nueva relación laboral (quedando a la espera de la notificación de la Jefatura Provincial de Tráfico, que obliga a estos trabajadores a permanecer inactivos durante dicho lapso temporal). La Federación sindical no impugnó el régimen autorizatorio sobre cuya base descansaba el Reglamento, si no que meramente cuestionó el criterio utilizado en el mismo el cambio de escuela-, como verdadero "elemento objetivo, equilibrado y razonable" que justificara la exigencia de renovación de la autorización.

En lo relativo a la documentación que debía acompañar a las solicitudes de autorización de ejercicio del personal directivo y docente de las escuelas de conductores, el Reglamento exigía, entre otros, que se aportara el certificado de aptitud de Director de escuelas particulares de conductores o de profesor de formación vial o de profesor de escuelas particulares de conductores. Este extremo, que sí fue cuestionado por la parte -demandante por entender que hubiera sido suficiente una comunicación previa o una declaración responsable- permite, como veremos, observar uno de los principales efectos de la presentación de las declaraciones responsables: en no pocas ocasiones se prevé la utilización de esta técnica no para facultar el inicio de actividades sino como complemento de otras medidas de intervención; en esta ocasión, de una autorización ${ }^{11}$.

\footnotetext{
${ }^{11}$ Otro ejemplo de establecimiento normativo de una declaración responsable como técnica que acompaña a la transmisión de otro título habilitante lo encontramos en la sentencia de la Audiencia Nacional de 27 de marzo de 2014 (número de recurso 505/2012). Pescadores de Carboneras, S.C.A. impugna la Orden ARM/1753/2011, de 22 de junio, por la que se regula la pesquería de atún rojo en el Atlántico Oriental y Mediterráneo. El artículo 6 apartado 3 de dicha orden establece que la solicitud de las posibilidades de pesca debe ir acompañada de una declaración responsable suscrita por el armador del buque cedente, en la que se compromete a revertir en su tripulación una parte del ingreso generado por la transmisión de las posibilidades de pesca (de acuerdo con el sistema de retribución proporcional en función de las capturas). Entre otros motivos, se solicita la nulidad de este precepto de la Orden por vulneración del principio de jerarquía normativa, desviación de poder e in-
} 
El Tribunal Supremo no desaprovecha la ocasión para reflexionar y dar, en cierto sentido, razón a los recurrentes cuando admite que "es cierto que podía haberse optado por otras técnicas diferentes para conseguir la misma finalidad. Sugiere la recurrente, en concreto, que hubiese sido suficiente con una declaración responsable o comunicación previa o que bastaría con reconocer un período de validez determinado a las autorizaciones de ejercicio ya concedidas. Y sin duda alguna estas soluciones contribuirían a simplificar el procedimiento y a hacerlo menos oneroso o incómodo para el administrado. Pero ello no implica que la opción elegida por el titular de la potestad reglamentaria, con la cobertura normativa antes reflejada, sea ilegal o vulnere una norma de rango superior"12.

El órgano judicial confirma, citando literalmente lo expresado por la parte demandante, la suficiencia de una declaración responsable o comunicación previa; pero no va más allá. Es decir, está de acuerdo en que se podían haber utilizado estas técnicas, pero no entra en si en el caso concreto procedería una u otra.

Dentro de este grupo de sentencias en las que se ha enjuiciado la oportunidad o no de mantener el régimen autorizatorio o sustituirlo por el de declaración responsable o comunicación previa cabe añadir la sentencia núm. 294/2011, de 6 de julio, del Tribunal Superior de Justicia de La Rioja, en la que se enjuicia la legalidad de concretos preceptos, en esta ocasión, de una Ordenanza ${ }^{13}$.

Vodafone España SAU interpuso recurso contencioso administrativo contra el Acuerdo del Pleno del Ayuntamiento de Logroño por el que se aprobó defini-

fracción del artículo 33 de la CE; argumentando que la exigencia contenida en dicho artículo no tiene sustento en ninguna norma, "ya que no está establecido en lugar alguno que el armador haya de revertir en la tripulación, parte de los ingresos generados por la transmisión de posibilidades".

Procede el Tribunal a analizar la legislación vigente relativa la transmisibilidad de posibilidades de pesca. La Ley estatal de pesca del año 2001 remite al procedimiento que reglamentariamente se determine; que tendrá en cualquier caso en cuenta una serie de criterios. Dentro de estos criterios no se halla, en efecto, la obligación materializada o cursada a través de dicha declaración responsable. Reconoce que la Ley remite al desarrollo reglamentario y que la Orden concreta el procedimiento, sin embargo resuelve la falta de sentido de que se exija esa declaración junto con la solicitud de transmisión de posibilidades de pesca cuando, en realidad, no existe ni la obligación formal de reparto ni mucho menos la que determine la parte de ingreso que se debe repartir. Declara el órgano judicial, así, la nulidad del precepto de la Orden recurrida.

${ }^{12}$ Fundamento jurídico sexto.

${ }^{13}$ Esta sentencia que comentaremos es idéntica, en estos extremos, a la posterior sentencia del Tribunal Superior de Justicia de La Rioja núm. 358/2011, de 5 de octubre, en la que la demandante fue Telefónica Móviles España S.A. 
tivamente la Ordenanza sobre instalaciones de los equipos y elementos de telecomunicación en ese municipio.

La parte demandante pretendía, entre otros muchos, la nulidad del artículo 18 de la reglamentación local, por cuanto contemplaba la exigencia de licencia de primera ocupación y funcionamiento una vez finalizada la obra e instalación con carácter previo a la puesta en servicio de la actividad. La consideró contraria a la Directiva 2006/123/CE de Servicios y a la Ley 17/2009, sobre libre acceso a las actividades de servicios y su ejecución.

El Tribunal repasa el contenido de los artículos 5 y 11 de la Ley paraguas -dedicados respectivamente a los requisitos de no discriminación, necesidad y proporcionalidad de los regímenes autorizatorios y a lo que se entiende, a efectos de esa ley, como razón imperiosa de interés general-, y el artículo 84 de la Ley 7/1985, reguladora de las bases de régimen local, en el que se regulan los medios de intervención de las entidades locales en la actividad de los ciudadanos. Tras dicho recordatorio, acaba concluyendo que "la exigencia de licencia de primera ocupación y de funcionamiento no resulta discriminatoria en función de la nacionalidad o del territorio, ni por razón de lugar de ubicación del domicilio social". Asimismo, constata que dicho régimen queda justificado por la existencia de una razón imperiosa de interés general, siendo "un medio para proteger la salud pública, el medio ambiente, el entorno urbano o el patrimonio cultural". Su argumentación se cierra con una afirmación importante con relación a la autorización, pues la concibe como "el instrumento más adecuado para garantizar la consecución del objetivo que se persigue, pues es la forma más segura para comprobar que lo ejecutado coincide con lo autorizado y que ha sido previamente examinado".

En esta ocasión, el Tribunal Superior de Justicia de La Rioja, a diferencia de lo hecho por Tribunal Supremo en la primera sentencia analizada asume, en cierto modo, la tarea de justificar la presencia de una razón imperiosa de interés general. En otras palabras, no excluye su existencia solo por la falta de manifestación expresa de la misma en la normativa reglamentaria local.

A distinta conclusión llega el Tribunal Superior de Justicia de Madrid en la sentencia núm. 1663/2012, de 29 de noviembre. Vodafone España S.A., impugnó la Ordenanza técnica de instalación y funcionamiento de infraestructuras radioeléctricas de Paracuellos del Jarama. Se solicitó la nulidad de esta disposición o subsidiariamente la de concretos artículos, siendo en los que incidiremos los referentes a la exigibilidad de licencias para instalaciones de telecomunicaciones.

Reproduce el Tribunal Superior, en este sentido, aquello dispuesto por el Tribunal Supremo que se resume en no exigir, por los Ayuntamientos, licencia de ac- 
tividades clasificadas para la instalación de antenas de telefonía móvil; entre otros, en aplicación del principio de precaución y sobre todo "por razones de índole competencial y razones de dinámica de la propia licencia de actividad que impediría a los municipios exigir tal licencia"14.

Lo interesante, lo que realmente añade el Superior de Justicia a esta doctrina del Supremo -y que justifica como un "plus" la inexigibilidad de estas licenciases la referencia a la normativa de libre acceso a las actividades de servicios y su ejercicio. Incide en especial en la nueva redacción del artículo 84 de la LRBRL ${ }^{15}$; concluyendo, a mayor abundamiento, que al tiempo de publicación de la Ordenanza ya no era exigible la licencia de actividad, pudiendo someterse esta a otro régimen de control como la comunicación previa y la declaración responsable. Recalca la distinción entre la licencia de actividad y de obra mayor o menor. Al ser esta última de contenido urbanístico -y sin dudar de la competencia de los Ayuntamientos en dicha materia-, reitera su vigencia al no haberse visto modificado su régimen por la normativa de transposición de la Directiva; y anula sólo los segmentos de los artículos impugnados relativos a la licencia de actividad o apertura $^{16}$ y a la licencia de funcionamiento ${ }^{17}$.

${ }^{14}$ Fundamento jurídico decimosexto.

${ }^{15}$ Entre otros, MOREU CARBONELL, E., "La Administración "neopolicial": autorización administrativa y sistemas alternativos: comunicación previa y declaración responsable", Monografias de la Revista Aragonesa de Administración Pública XII, 2010, p'gas. 249-295. FERNÁNDEZ TORRES, J. R., "Regímenes de intervención administrativa: autorización, comunicación previa y declaración responsable", Revista catalana de Derecho público núm. 42, 2011 , págs. 85-114; NÚÑEZ LOZANO, M. G., "Aproximación al régimen jurídico de las declaraciones responsables y comunicaciones", Noticias de la Unión Europea núm. 317, 2011, págs. 107-123; MORA RUIZ, M., "Comunicación previa, declaración responsable y control posterior de la actividad en el ámbito local: aproximación a su régimen jurídico ¿nuevas técnicas administrativas?, Revista española de Derecho administrativo núm. 155, 2012, págs. 237-276, y SOCIAS CAMACHO, J. M., "El nuevo modelo de intervención administrativa en el ámbito local", Revista Aragonesa de Administración pública núm. 41-42, 2013, págs. 67-90.

${ }^{16}$ Termina el Tribunal discurriendo sobre el precepto de la Ordenanza que preveía la necesidad de aportar autorización del titular del inmueble donde se ubicara la instalación mediante copia del contrato privado suscrito. Dicho artículo se declara nulo, en primer lugar por contradecir en sí mismo lo dispuesto en el Decreto de 17 de junio de 1955 por el que se aprueba el Reglamento de Servicios de las Corporaciones Locales, articulo 12, que entiende que las autorizaciones y licencias se entenderán otorgadas salvo el derecho de propiedad y sin perjuicio de terceros; y en segundo lugar por ir referido a la licencia de actividad que desaparece. Fundamento jurídico vigésimo segundo.

${ }^{17}$ Reproduciendo los mismos argumentos encontramos la STSJ de Madrid núm. 229/2013, de 20 de febrero -Telefónica Móviles España S. A. contra la Ordenanza Técnica de Instalación y funcionamiento de infraestructuras radioeléctricas de Paracuellos del Jarama-; STSJ de Madrid núm. 
En la sentencia del Tribunal Superior de Justicia de Castilla y León, de 17 de diciembre de 2013 (núm. rec. 1783/2011), vemos un caso opuesto en el que la parte demandante alega la procedencia de visado obligatorio, oponiéndose a la instauración de la figura de declaración responsable. El Consejo de Colegios Profesionales de Peritos e Ingenieros Técnicos Industriales de Castilla y León impugnó la desestimación (primero presunta y posteriormente expresa) de un recurso de alzada interpuesto contra la Instrucción de 7 de febrero de 2011 sobre "interpretación del visado obligatorio de proyectos y demás trabajos profesionales firmados por Técnicos Titulados competentes, de acuerdo con lo previsto en el Real Decreto 1000/2010, de 5 de agosto. Necesidad de presentación de declaración responsable suscrita por el Técnico titulado competente en el caso de que los documentos no se visen".

El Consejo de Colegios pidió la nulidad de estas instrucciones en la medida que, muy resumidamente, entendió que la declaración general de no obligatoriedad del visado colegial provenía de una interpretación "excesivamente rigorista y literal" de las previsiones del RD del año 2010 antes citado, sobre visado colegial obligatorio y

561/2013, de 8 de mayo -France Telecom España S. A contra la Ordenanza Técnica de Instalación y funcionamiento de infraestructuras radioeléctricas de Paracuellos del Jarama-; y STSJ de Madrid núm. 818/2013, de 19 de junio de 2013 -Vodafone España S.A.U contra la Ordenanza municipal reguladora del emplazamiento, instalación y funcionamiento de equipos para la prestación y uso de los servicios de telecomunicaciones de Leganés-. Estos fundamentos se reiteran, asimismo, en la STSJ de Madrid núm. 1598/2013, de 18 de diciembre, pero en relación no con la impugnación de una ordenanza sino para el supuesto de una actividad (estación base de telefonía móvil) que disponía de licencia de apertura y obra pero no de funcionamiento; y respecto la cual el juzgado de lo contencioso había confirmado la resolución administrativa de demolición de las antenas. A todo ello el TSJ de Madrid revoca la sentencia apelada.

En un caso parecido a los primeros indicados, el TSJ de Navarra en sentencia núm. 31/2014, de 6 de febrero -Telefónica Móviles España S.A. contra la Ordenanza municipal sobre instalaciones e infraestructuras de telefonía móvil en el Municipio de Tudela-, declara la nulidad de los preceptos de esta disposición bastándose tanto de lo dicho por el TS como lo dicho por el TSJ de Madrid en sentencia de 9 de junio de 2013 (que no es sino reproducción de la sentencia núm. 1663/2012, de 29 de noviembre, comentada en el texto principal de este trabajo). A su vez la sentencia del TSJ de Navarra núm. 117/2014, de 27 de febrero, reproduce lo dicho por la propia Sala en la sentencia núm. 31/2014, de 6 de febrero.

Otra sentencia que, con contenido distinto, tiene por objeto el reproche a la no inclusión de los sistemas de comunicación previa y declaración responsable en una ordenanza municipal en sustitución del autorizatorio, es la del TSJ de País Vasco núm. 261/2013, de 8 de mayo de 2013. Esta sentencia es, además, un claro ejemplo de desaparición del objeto del recurso directo contra una Ordenanza por derogación sobrevenida de la misma por adaptación de la normativa posterior a la Directiva de Servicios. 
su inexigibilidad en instalaciones de seguridad industrial. Cuestionó el establecimiento del visado como excepcional al obviarse su propia finalidad; y consideró improcedente la figura de la declaración responsable como documento sustitutivo del mismo $^{18}$.

El TSJ, sin embargo, no admitió estar ante un "error de interpretación"; añadiendo que lo que pretendía la demandante era contrario a la propia literalidad de las normas analizadas y su finalidad. La finalidad no era otra que la de establecer el carácter voluntario del instrumento del visado y la potestad del Gobierno de considerarlo -en ciertos supuestos afectantes a la integridad física y salud de las personas-, como el medio de control más proporcionado y por tanto obligatorio.

La Disposición Final Tercera de la Ley 17/2009, de 23 de noviembre, sobre libre acceso a las actividades de servicios y su ejercicio -que según la parte demandante permitiría a las Comunidades Autónomas establecer en su territorio el visado obligatorio- no facultaba, en opinión del órgano judicial, que las Administraciones dictaran normas de desarrollo y ejecución que pudieran contravenir los supuestos tasados de visado obligatorio. Así, discurre acerca del margen de desarrollo de las normas autonómicas en el ejercicio de competencias sectoriales ${ }^{19}$;

18 Antes de entrar en el fondo del asunto, el Tribunal valora dos cuestiones importantes, ambas relacionadas directa o indirectamente con los límites del control jurisdiccional.

La primera de estas cuestiones guarda relación con la propia naturaleza del acto impugnado: una instrucción. Como bien manifiesta el Tribunal, no tienen las instrucciones naturaleza de disposiciones de carácter general, sino que albergan directrices de funcionamiento, interpretación y aplicación jurídica emanadas de órganos superiores en el ejercicio de sus potestades administrativas domésticas hacia la actividad de sus subordinados o dependientes. No constituyen normas jurídicas, generalmente no son publicadas, no innovan el Ordenamiento jurídico y carecen, en principio, de relevancia para terceros. Se entiende, -recordando un pronunciamiento previo de la misma Sala-, que no queda cerrada la posibilidad de impugnación del criterio que una instrucción contiene, pudiendo plantearse recursos contra actos administrativos concretos que lo apliquen. Sin embargo, considera el Tribunal que el caso concreto se desmarca de esta opción impugnatoria de las instrucciones y accede al control de la legalidad de la misma "en la medida que el contenido de la instrucción que ahora nos ocupa contiene un contenido referente a la interpretación de preceptos legales que establecen la obligatoriedad del visado" (...) afectando "tanto a la actividad propia de los Colegios integrados en el Consejo demandante como a sus propios cometidos, produciendo en este sentido así efectos "ad extra"".

La segunda cuestión importante, da pistas ya sobre el sentido de la propia decisión del Tribunal cuando, tras la lectura de los fundamentos de la demanda, advierte que el criterio interpretativo discrepante del demandante lo que en realidad plantea son "aspectos que rigen por el principio de oportunidad y que escapan al control jurisdiccional". Fundamento jurídico cuarto.

19 CANALS AMETLLER, D., "Reforma de la Administración pública y unidad de mercado: incidencias en el régimen de intervención municipal en la actividad económica privada", Cuadernos de Derecho local núm. 36, págs. 28-46. 
para concluir que éstas, en materia colegial como en otras, quedan obligadas a respetar las bases estatales ${ }^{20}$.

El Tribunal Superior recuerda lo establecido en la Sentencia del Tribunal Supremo de 22 de enero de 2013 acerca de la naturaleza del visado: "Se reduce, pues, conforme el vigente artículo 13.2 de la Ley 2/1974, a meras constataciones de carácter formal y de ningún modo abarca los aspectos esencialmente técnicos o facultativos de las actuaciones sujetas a él. $\mathrm{Al}$ visar un determinado proyecto el Colegio profesional podrá constatar si su autor goza de habilitación al efecto y si en aquél se incluyen los documentos que le han de acompañar pero mediante el visado colegial no puede controlar técnicamente la corrección de sus elementos facultativos". Continuando con la referencia a la doctrina del TS, considera que existen medios o procedimientos "menos onerosos" que la sujeción obligatoria a visado colegial que permiten, de igual forma "verificar la identidad y habilitación profesional del autor del trabajo o la corrección e integridad formal de los documentos en que aquél se plasma"21.

Llegados a este punto, el TSJ de Castilla y León aborda la segunda cuestión planteada por la parte demandante relativa al cuestionamiento de la declaración responsable como alternativa al visado colegial. Considera, en primer lugar, que el argumento de la parte de que "la regulación pudo hacerse de otra manera distinta" no fundamenta jurídicamente la improcedencia o contravención de la legalidad de la instauración del sistema de declaración responsable. Un sistema que se reitera no fue ni creado ex novo ni introducido por la mencionada Instrucción sino por las normas ya mencionadas -entre ellas el RD de 2010- que establecen con carácter general el visado no obligatorio. Y siendo tasados los supuestos en que sí resulta éste preceptivo, no cabe la ampliación de los mismos.

\footnotetext{
${ }^{20}$ Se remite en este punto a la Sentencia del Alto Tribunal de 22 de enero de 2013 para destacar, entre otros, que el visado colegial obligatorio es una "técnica de control mediante la que los Colegios ejercen funciones administrativas coherentes con su cualidad de corporaciones de Derecho público", y que nada impide que las Comunidades Autónomas y Corporaciones locales "puedan regular otros medios de control propio distintos del visado colegial obligatorio, o incluso, en ejercicio de su autonomía organizativa, pactar con los colegios profesionales los convenios correspondientes o contratar con ellos la prestación de los servicios de comprobación documental, técnica o sobre el cumplimiento de la normativa aplicable que consideren necesarios relativos a los trabajos profesionales". Fundamento jurídico séptimo.

21 Termina así con el ejemplo del control documental que pueden llevar a cabo las oficinas de control de proyectos de las Administraciones públicas o las entidades de certificación y control; y en lo relativo a los datos personales, el recurso a los registros actualizados de profesionales colegiados.
} 
En último lugar responde el Tribunal, de forma poco entendedora baste decir, a las alegaciones del Consejo relativas al tema de la responsabilidad. Plantea el demandante la equiparación en la Instrucción de la responsabilidad del Colegio por un trabajo visado y un no visado "pretendiéndose cubrir las mismas responsabilidades subsidiaras legalmente exigibles a los Colegios profesionales por los daños causados por un profesional colegiado, cuando es lo cierto que las aseguradoras asumirían una responsabilidad no subsidiaria sino directa en los supuestos en que el autor del trabajo fuere el asegurado de la póliza ${ }^{22}$.

En este punto, como avanzábamos, la respuesta del Tribunal queda visiblemente corta. Desde nuestro punto de vista aun entendiéndose que se trataba, también en esta ocasión, de una cuestión estrictamente de "oportunidad" u opción regulatoria de normas ajenas a la instrucción -como se reitera a lo largo de la sentencia-, merecía este extremo una mejor aclaración o interpretación. Reproduce el órgano judicial, no obstante, el apartado correspondiente de la Instrucción relativo a la responsabilidad y añade simplemente que "en la Instrucción no se establece ninguna obligación de que los autores de la declaración responsable tengan que suscribir algún seguro, sino que simplemente en el modelo del anexo se contempla un apartado para indicar (marcando una X en el "SI" o "NO") si el profesional tiene o no suscrita póliza de responsabilidad civil" ${ }^{23}$. La desestimación del recurso es la decisión final del Tribunal.

Otra resolución que, por último, puede traerse a colación es la sentencia del Tribunal Superior de Justicia del País Vasco núm. 210/2013, de 9 de abril de 2012, sobre vías pecuarias. En esta sentencia, entre otros, se impugna un precepto de la Ordenanza del Ayuntamiento de Busturia reguladora de la utilización de los caminos rurales con vehículos pesados, por el cual se "sujeta a licencia la

\footnotetext{
${ }^{22}$ En este sentido cuestiona el punto 7 del modelo de Declaración responsable que se contiene en el Anexo, y ello en cuanto señala que el periodo de validez de la póliza cubre la vida útil de la instalación proyectada/ejecutada, toda vez que contraviene por aplicación analógica el artículo 1583 in fine del Código Civil; y lo que además, se dice, no pasa de ser una pretensión quimérica en que sólo se recoge una aseveración de que existe seguro, sin que por tanto quede garantizado la cobertura del concreto trabajo realizado, viéndose así comprometida la protección constitucional de los usuarios recogida en el artículo 51.1 de la Constitución, y abocándose además a la Administración a asumir la responsabilidad por los eventuales daños y perjuicios derivados de una obra y servicio no visado y cubierto por esa declaración responsable. Y al final, a modo de conclusión, se termina recordando que la Administración está constitucionalmente obligada a velar por el cumplimiento de las normas reguladoras de las atribuciones profesionales"

${ }^{23}$ Fundamento jurídico octavo.
} 
utilización de los caminos rurales de propiedad municipal por vehículos de peso por eje superior a tres toneladas".

El Tribunal entiende que la utilización de caminos rurales constituye un uso común especial sujeto a licencia (arts. 75 y 77 del Real Decreto 1372/1986, de 13 de junio, por el que se aprueba el Reglamento de bienes de las Entidades locales), sin que pueda considerarse una actividad de prestación de servicios sujeta al régimen de comunicación previa o declaración responsable. Lo justifica en base al artículo 84 de la Ley 7/1985, de 2 de abril, reguladora de las bases del régimen local, que tras la modificación obrada por la Ley 2/2011, de 4 de marzo de economía sostenible, faculta a las entidades locales para someter a licencia o acto de control preventivo las actividades que impliquen el uso privativo y la ocupación de los bienes de dominio público.

No entiende trasladable el régimen de declaración responsable vigente para la utilización de estas vías por vehículos motorizados en el ejercicio de una actividad de servicios -que instauró la Ley 25/2009, de 27 de diciembre-, al caso de su uso por vehículos pesados (en el supuesto concreto, derivado de la actividad de explotación forestal o silvicultura). Añade, además, que el objeto de la licencia no es la actividad primaria o estractiva de la silvicultura, sino la circulación de dichos vehículos pesados por vías rurales.

En definitiva, considera el órgano judicial que el régimen de autorización se ampara en la habilitación legal posterior a las leyes de transposición de la Directiva de Servicios. Esta norma comunitaria no alberga un contenido normativo que no sea disponible por el legislador interno, que ampare el derecho invocado por la recurrente (la Asociación Mesa Intersectorial de la Madera de Euskadi) de oposición al régimen de control previo establecido por la norma que se recurre ${ }^{24}$.

\section{APLICACIÓN EXTENSIVA DEL RÉGIMEN JURÍDICO DE LA DEGLARACIÓN RESPONSABLE Y LA COMUNICA- CIÓN PREVIA AL CONTEXTO DE ACTIVIDADES INICIA- DAS SIN LA OBLIGATORIA LICENCIA}

En segundo lugar, como avanzábamos, vamos a destacar una serie de resolu-

\footnotetext{
${ }^{24}$ Fundamento jurídico quinto.
} 
ciones -principalmente del Tribunal Superior de Justicia de Madrid- por la, cuanto menos, peculiar aplicación de las previsiones de la Ley 30/1992 relativas a la comunicación previa y la declaración responsable; y también porque, de un modo un tanto inesperado, contribuyen a delimitar aspectos básicos del régimen de estos institutos ${ }^{25}$.

Tomaremos como ejemplo la sentencia del Tribunal Superior de Justicia de Madrid núm. 1909/2011, de 22 de diciembre. A pesar de no ser la primera es, de todas ellas, la que ofrece más pistas sobre el porqué se utiliza el contenido del artículo 71 bis de la Ley de procedimiento como razonamiento para resolver un caso con en el que, por lo menos en apariencia, nada tiene que ver. Sea como sea, todas las sentencias tienen en común que tratan recursos de apelación por denegación de la suspensión cautelar de la ejecutividad de distintas resoluciones administrativas ${ }^{26}$.

Se había solicitado al juzgado contencioso administrativo núm. 3 de Madrid la suspensión cautelar de la ejecutividad de la resolución de la Gerencia Municipal de Urbanismo de Móstoles que ordenaba la clausura de una actividad titularidad de Maxichina Móstoles S.L.; medida que fue denegada.

El Tribunal Superior recuerda la doctrina del Tribunal Supremo ${ }^{27}$ al constatar, entre otros, que "al tratarse de una actividad desarrollada sin licencia, no procede suspender la ejecutividad del acuerdo municipal impugnado ya que, en caso de acordarla, haríamos una declaración de naturaleza positiva, accediendo al otorgamiento de una licencia denegada por el tiempo que durara la tramitación

${ }^{25}$ Entre otros, LÓPEZ MENUDO, F., "La transposición de la Directiva de Servicios y la modificación de la Ley 30/1992: el régimen de la declaración responsable y de la comunicación previa”, Revista española de la función consultiva núm. 14, 2010, págs. 111-150.

${ }^{26}$ Sentencias del Tribunal Superior de Justicia de Madrid: sentencia núm. 1907/2011, de 22 de diciembre de 2011; sentencia núm. 1908/2011, de 22 de diciembre de 2011; sentencia núm. $1165 / 2012$, de 19 de julio de 2012; sentencia núm. 1356/2012, de 4 de octubre de 2012; sentencia núm. 6/2013, de 10 de enero de 2013; sentencia núm. 225/2013m de 20 de febrero de 2013, y sentencia núm. 347/2014, de 2 de abril de 2014.Véase también la Sentencia del Tribunal Superior de Justicia de Galicia núm. 5882/2012, de 21 de junio y la Sentencia del Tribunal Superior de Justicia del País Vasco núm. 391/2012, de 9 de agosto.

${ }^{27}$ Auto del Tribunal Supremo de 25 de julio de 1995, y Autos de 19 de julio y 5 de noviembre de 1991; Sentencia del Tribunal Supremo, en adelante, TS, de 21 de septiembre de 1988; STS de 18 de julio de 1986; STS de 5 de mayo de 1987; STS de 4 de julio de 1995; STS de 20 de diciembre de 1987; STS de 20 de enero de 1989; STS de 9 de octubre de 1979; STS de 31 de diciembre de 1983 y STS de 4 de julio de 1995. 
del recurso" y que -continuando con la referencia a la jurisprudencia del Alto Tribunal- "el ejercicio de este derecho de actividad ha de atenerse a los limites configurados por el ordenamiento jurídico, y por tanto al límite temporal establecido y (...) ni el transcurso del tiempo, ni el pago de tributos, tasas o impuestos, ni la tolerancia municipal, implican acto tácito de otorgamiento de licencia, conceptuándose la actividad ejercida sin licencia como clandestina e irregular que no legitima el transcurso del tiempo, pudiéndose acordar la paralización o cese de tal actividad por la autoridad municipal en cualquier momento"28.

Lo que llama la atención de esta y las otras sentencias es que, en el fundamento jurídico quinto de todas ellas, el Tribunal procede a un amplio y completo repaso de la normativa relativa a la declaración responsable y comunicación previa (empezando por el contenido del artículo 84 de la LRBRL y terminando con el del artículo 71 bis de la Ley 30/1992); sin que, en realidad, ninguna de estas técnicas sea la aplicable a los casos enjuiciados.

En particular, del artículo 71 bis se destaca aquel apartado en el que se establece que la inexactitud, falsedad u omisión de carácter esencial de cualquier dato, manifestación o documento que se acompañe o se incorpore a una declaración responsable o a una comunicación previa, o la no presentación ante la Administración competente de las mismas, determinará la imposibilidad de continuar con el ejercicio del derecho o actividad afectada desde el momento en que se tenga constancia de tales hechos.

El TSJ de Madrid es tajante en cuanto el requisito de previa licencia para acordar la suspensión; dicho de otro modo, la no posesión de licencia de funcionamiento para la actividad hace imposible suspender la clausura por los motivos antes apuntados; aunque pueda haber matices ${ }^{29}$. Sorprende, sin embargo, el re-

\footnotetext{
${ }^{28}$ Fundamento jurídico tercero y cuarto.

${ }^{29}$ La STJ de Madrid núm. 1907/2011, de 22 de diciembre, constituye ejemplo de la aplicación del principio de proporcionalidad en la adopción de la medida menos gravosa. Dicho de otro modo, es ejemplo de estos "matices" apuntados cuando la norma prescribe la imposibilidad de continuar con el ejercicio de derechos o actividades afectados por alguno de los defectos en la comunicación o declaración responsable (aunque en realidad se trate en este caso, como en todos, de actividades clandestinas por la no obtención de licencia). En este caso particular, la Administración no determinó la clausura de toda la actividad por considerar dicha medida contraria al principio general citado, entendiendo suficiente la retirada de los concretos elementos industriales no licenciados. Fundamento jurídico quinto.
} 
curso jurídico a la previsión del 71 bis que prevé la imposibilidad de continuar con el ejercicio de la actividad respecto la que no se ha presentado comunicación previa o declaración responsable alguna, desde el momento en que se tenga constancia de tal circunstancia.

Esta sentencia del TSJ de Madrid aclara, además, las dudas sobre la obligatoriedad del trámite de audiencia (antes de la clausura) cuando determina que "no existe prueba alguna que contradiga dichos hechos y por tanto el efecto jurídico no puede ser otro que el señalado en el artículo 71 bis de la Ley 30/1992 (...) es decir la imposibilidad de continuar con el ejercicio del derecho o actividad afectada sin que pueda deferirse el mismo a la tramitación de expediente con trámite de audiencia pues la propia Ley fija el momento temporal en que se ha de producir dicho cese al señalar que este cese ha de producirse desde el momento en que se tenga constancia de tales hechos" ${ }^{\prime \prime}$.

Esta última previsión se contradice frontalmente con aquello dispuesto por el mismo Tribunal en sentencia núm. 1356/2012, de 4 de octubre: "la clausura de una actividad ejercida sin licencia (o declaración responsable en la actualidad en algunos casos) es una medida cautelar que ha de adoptarse previa audiencia del interesado, por ello ha de rechazarse el argumento de que el acto es nulo por lesionar derechos fundamentales, ya que no nos encontramos ante un supuesto de sanción sino una medida cautelar, por lo que difícilmente puede infringirse el principio de tipicidad o legalidad".

En el mismo sentido se pronuncia de nuevo el Tribunal en la sentencia núm. 6/2013, de 10 de enero ${ }^{31}$; añadiendo algo relevante ligado al trámite de audiencia pero también a otro eventual trámite: el requerimiento de legalización.

${ }^{30}$ Fundamento jurídico quinto.

${ }^{31}$ A diferencia de lo ya comentado respecto la ausencia de licencia de actividad como obstáculo a la solicitud de suspensión, el Tribunal Superior de Justicia de Madrid no es tan implacable cuando lo que se debate es el acuerdo de suspensión de actos administrativos de contenido o finalidad distinta; como puede ser la ejecución de una sanción económica -STSJ de Madrid núm. 1908/2011 de 22 de diciembre- o la orden de demolición y/o desmontaje de instalaciones -STSJ de Madrid núm. 225/2013, de 20 de febrero, que seguidamente veremos-.

Distinto es, en efecto, el caso de la petición de suspensión de la ejecución de una sanción pecuniaria, a la que junto con la solicitud de suspensión de la medida cautelar de paralización del ejercicio de actividades, apela el recurrente en la sentencia del TSJ de Madrid núm. 1908/2011 de 22 de diciembre. Respecto a la misma, resuelve el Tribunal que "sólo en supuestos excepcionales, en que por la importancia de la sanción pecuniaria, unida a la situación financiera acreditada de la persona o entidad obligada al pago, pudiera peligrar con la ejecución la estabilidad económica del que debe satisfacerla, u ocasionar otro perjuicio difícil de indemnizar en el caso de una eventual estima- 
En este caso, constata el Tribunal una aplicación improcedente de la normativa urbanística por el Ayuntamiento de Las Rozas. Brinda éste a la demandante (que había iniciado una actividad sin la preceptiva autorización) la oportunidad de, en el plazo de dos meses, solicitar la licencia de funcionamiento. La conclusión del órgano judicial es que "el ejercicio de una actividad sin licencia no es equiparable a la implantación de un uso urbanístico"32. El precepto invocado por la entidad local contenía la medida cautelar de suspensión de actos de edificación o uso del suelo realizados sin licencia u orden de ejecución; juzgándose inaplicable al supuesto en cuestión (que se refería a las condiciones de ejercicio de una actividad y no a una licencia urbanística o a las condiciones urbanísticas de la misma).

La parte recurrente alegó la nulidad de pleno derecho del acto administrativo objeto de recurso -la denegación de la suspensión- por haberse dictado prescindiendo total y absolutamente del procedimiento establecido "pues la construcción de cualquier obra sin licencia debe seguir la Ley del suelo de Madrid". A este argumento respondió el órgano judicial de manera rotunda "cuando se trata de una actividad que carece de licencia de instalación o declaración responsable o comunicación previa el procedimiento no es el que la parte indica y no se precisa requerimiento de legalización alguno sino una mera audiencia pues la clausura es una medida cautelar".

Citando sentencias precedentes de casos muy parecidos añadió el Tribunal que el procedimiento de restauración de la legalidad urbanística no era aplicable al caso y por lo tanto no cabía dictar "requerimiento de legalización alguno lo que es consustancial a la adopción de dicha medida cautelar". Advirtió así a la Administración, como colofón final, que el uso de potestades urbanísticas para otras finalidades constituía un supuesto indudable de desviación de poder ${ }^{33}$.

La STSJ de Galicia núm. 663/2012, de 21 de junio, trata de un caso en que la demandante recurre una orden de demolición de una construcción, dictada por la Administración, ante la falta de la licencia correspondiente.

ción del recurso, podría hacerse posible la aplicación de la medida de suspensión de la ejecución" (citando al respecto distintos autos del TS de 1991 y 1992). Considera finalmente, sin embargo, que la parte demandante no prueba que el pago de la suma de 600.000 euros ocasione tales perjuicios y por lo tanto desestima su petición. En el mismo sentido véase la STSJ de Madrid núm. 347/2014, de 2 de abril. Fundamento jurídico sexto y séptimo.

${ }^{32}$ Fundamento jurídico quinto.

${ }^{33}$ Fundamento jurídico sexto. 
Alega la parte que en ese momento, por aplicación de la normativa de servicios, no era ya exigible dicha licencia. A lo que le responde el Tribunal que, en primer lugar, no era aplicable todavía la Directiva de Servicios. En segundo lugar que, en caso de que sí fuera aplicable, no constaba la presentación por parte de la demandante de comunicación previa o declaración responsable alguna. Y en último lugar y más importante, discurre el órgano judicial acerca de la diferencia entre licencia urbanística y de actividad. Considera la orden de demolición como legal por ser dictada ante la ausencia de una licencia de obras; siendo esta la forma prevista por el Ordenamiento jurídico de restauración de la legalidad urbanística infringida, pero no la reacción jurídica adecuada frente la falta de una licencia de actividad (licencia que, por otro lado, nunca llegó a solicitarse).

La diferencia de régimen jurídico entre una y otra licencia puede verse claramente en la Sentencia del Tribunal Superior de Justicia de Madrid núm. 225/2013, de 20 de febrero. Lo que se recurre, y sobre lo que se solicita la suspensión, son dos resoluciones de la Administración: una por la que se acuerda el cese y clausura de una actividad de picadero de caballos y otra que ordena la demolición y/o desmontaje de las instalaciones. Respecto la primera medida, puesto que el Tribunal entiende que no consta que la actora estuviera en posesión de la licencia de funcionamiento de la actividad, no admite la suspensión de la clausura. En lo relativo a la orden de demolición apela a la doctrina jurisprudencial que, en supuestos de este tipo, accede a la suspensión de la ejecución del acto administrativo. La justificación es, principalmente, de tipo finalista: "toda orden de demolición por su propia naturaleza implica destrucción de riqueza material, por lo que, si se ejecuta antes de la culminación de proceso pendiente en el que ha de decidirse acerca de su procedencia y legalidad, puede dar lugar, en el caso de que quede revocada posteriormente a perjuicios de muy difícil reparación"34.

La conclusión, pues, a la que llegamos es que, según los tribunales, las actividades sometidas al régimen de comunicación previa o declaración responsable no gozan de este privilegio moratorio de adecuación a la legalidad que se circunscribe al ámbito urbanístico; del mismo modo que no disponen de él las actividades clandestinas o ejercidas sin licencia de funcionamiento o actividad cuyo régimen pasan a sustituir.

Destacaremos, por último, en este apartado, la sentencia del Juzgado de lo Contencioso-administrativo de San Sebastián núm. 179/2012, de 9 de agosto. Es este un caso complejo, no tanto desde un punto de vista jurídico como de narración y exposición de hechos y fundamentos. De este enrevesado conflicto de ac-

${ }^{34}$ Fundamento jurídico sexto. 
tividad sin licencia y orden de cierre -entre otros, por incompatibilidad del uso pretendido con la normativa urbanística en el que no nos vamos a detener-, pueden destacarse una serie de cuestiones.

La primera es una de las alegaciones de la parte recurrente relativa a la aplicabilidad de la normativa de servicios y la exención del requisito de autorización administrativa. Considera que ante su solicitud de permiso de actividad debía la Corporación haberle comunicado la improcedencia del mismo ${ }^{35}$; indicándole la necesidad de formular comunicación previa "sin que el desistimiento a la solicitud de licencia de actividad implicara renuncia por el recurrente a ninguno de sus derechos toda vez que la actividad no se sujetaría a licencia"36.

No entra el órgano judicial, sin embargo, a analizar la alegación de responsabilidad administrativa por falta de información. Se manifiesta, solo, sobre la indefensión producida a la parte recurrente en la tramitación del expediente que desembocó en la orden de clausura del establecimiento. Entiende, así, como segundo aspecto a destacar que "esa solicitud del particular no tramitada específicamente por la administración es la clave para estimar este recurso ya que evidencia la voluntad de ajustarse a la legalidad vigente al interesar que se inicien los trámites necesarios al respecto. Sin embargo, la administración, sin solución de continuidad, en lugar de iniciar el procedimiento para pronunciarse sobre la pretensión de la parte, incoa expediente sobre posible cierre, en el que (...) se emite la referida orden. Es decir, se causa indefensión al recurrente en cuanto que no se permite el control judicial del pronunciamiento por el que se deniega la actividad; que no es sino razonamiento implícito en la orden de cierre del establecimiento"37.

La argumentación que acabamos de ver entra en aparente contradicción con lo dispuesto por el Tribunal Superior de Justicia de Madrid en la sentencia núm. 6/2013, de 10 enero de 2013. Aún referido directamente al caso de autorizacio-

${ }^{35}$ La sentencia del Juzgado de lo contencioso administrativo de Bilbao núm. 167/2011, de 7 de junio de 2012 es también muestra del "caos" o "desconcierto" de los particulares, en ocasiones obligados a interpretar normas no suficientemente claras, a raíz de la introducción de las técnicas analizadas. En la base del conflicto judicial se halla el hecho de que el Ayuntamiento de Orozko resuelve negativamente, en primer lugar, una solicitud de licencia de actividad (para adiestramiento de perros de caza en una determinada parcela) y posteriormente rechaza la presentación "dual" (según la sentencia) o simultánea, de una declaración responsable y una comunicación previa para la misma actividad y por el mismo interesado. El Juzgado termina estimando el recurso y anulando la resolución denegatoria de la licencia, declarando el derecho del particular a su concesión por el Ayuntamiento.

${ }^{36}$ Fundamento jurídico primero.

${ }^{37}$ Fundamento jurídico cuarto. 
nes, debería reflexionarse si este aspecto del régimen de las mismas resulta aplicable al de las instituciones analizadas. Según el órgano judicial, deviene "intrascendente" que se haya solicitado a la Administración la nueva licencia antes de que ésta dicte el acto administrativo de suspensión, pues es preciso ostentar su posesión antes del inicio del ejercicio de la actividad, "siendo insuficiente la petición de licencia" 38 .

Este es un tema que nos puede llevar a plantear qué tipo de actuaciones de los particulares son susceptibles de detener o evitar la tramitación de una orden de cierre de establecimientos considerados clandestinos. En concreto, si la presentación posterior de la debida comunicación o declaración es suficiente para frenar las potestades administrativas otorgadas por la Ley de Procedimiento.

\section{EL SOMETIMIENTO DE LA ADMINISTRACIÓN PÚBLICA AL DEBER DE COMUNICACIÓN PREVIA}

En tercer lugar, quisiéramos destacar la sentencia de 1 de septiembre de 2011 (núm. rec. 180/2010), de la Audiencia Nacional por cuanto constituye, en primer lugar, un ejemplo del deber de sometimiento a comunicación previa no sólo de los sujetos privados sino también de la propia Administración pública; y en segundo lugar, por algunas de las consideraciones relativas a la funcionalidad de esta técnica interventora que realiza el órgano jurisdiccional.

El recurso contencioso administrativo lo presentó, en esta ocasión, el Ayuntamiento de Málaga contra la Comisión del Mercado de las Telecomunicaciones, por haberle impuesto una sanción de 300000 euros por infracción muy grave de la Ley General de Telecomunicaciones; intimándole, además, al pago de la tasa general de operadores de redes y a realizar la "notificación fehaciente" de inicio de actividad.

El problema radicaba en que el Ayuntamiento de Málaga inició en 2007 la explotación una red pública de comunicaciones electrónicas WIFI, y en 2008 la

\footnotetext{
${ }^{38}$ La pregunta es, ¿podría trasladarse este argumento a las técnicas que estudiamos? ¿Tendría los mismos efectos no suspensivos de una orden de paralización, la presentación de una comunicación o declaración posterior al inicio de una actividad pero previa a la medida administrativa cautelar? ¿Acaso no está prevista legalmente la modalidad de comunicación posterior? En relación con ésta última, ¿en qué momento podría decretar la Administración la clausura de la actividad? ¿Dependerá del límite temporal al que la someta la legislación que lo prevea expresamente?
} 
prestación del servicio de comunicaciones electrónicas de proveedor de acceso a Internet sin constar inscrito como operador en el Registro de operadores.

El artículo 6.2 de la Ley 32/2003, de 3 de noviembre, general de telecomunicaciones establece que "los interesados en la explotación de una determinada red o en la prestación de un determinado servicio de comunicaciones electrónicas deberán, con anterioridad al inicio de la actividad, notificarlo fehacientemente a la Comisión del Mercado de las Telecomunicaciones en los términos que se determinen mediante Real Decreto, sometiéndose a las condiciones previstas para el ejercicio de la actividad que pretendan realizar. Quedan exentos de esta obligación quienes exploten redes y se presten servicios de comunicaciones electrónicas en régimen de autoprestación”.

El núcleo del litigio fue, entonces, dilucidar si la actividad del Ayuntamiento a través de la red pública de comunicaciones electrónicas y la prestación de servicios de acceso wifi se podía considerar, o no, incluida en la noción de "autoprestación".

La Audiencia Nacional llegó a la conclusión que no, que dicha entidad local no podía verse beneficiada de la exclusión del deber de "comunicación fehaciente" de la actividad "que dimanaría de su calificación como autoprestación"39; y que, por lo tanto, quedaba sometida al deber de "declaración de inicio de actividad" e inscripción en el Registro de operadores.

Añadió a su argumentación que "la comunicación fehaciente y la inscripción en el Registro de operadores no es un mero formalismo o una irrazonable traba administrativa sino que constituye un instrumento para controlar el acceso al mercado, fiscalizar el desarrollo de actividades en dicho mercado y para que dicha Comisión pueda ejercer sus funciones" (...) "En el caso de las Administraciones públicas, aquella comunicación previa posibilita el control de determinadas obligaciones adicionales a las que pueden quedar sujetas para la prestación de servicios de comunicaciones electrónicas, como es la separación de cuentas y su deber de actuar con neutralidad, transparencia y no discriminación, así como el deber de sujetar su actividad al principio de "inversor privado", acuñado por la jurisprudencia del Tribunal de Justicia de la Unión Europea" ${ }^{\prime 4}$.

\footnotetext{
${ }^{39}$ Fundamento jurídico tercero, apartado 6.3.

${ }^{40}$ Fundamento jurídico tercero, apartado 6.3.
} 
Además de las apreciaciones de la Audiencia relativas a las funciones de la según el léxico utilizado en el último párrafo trascrito- "comunicación previa", destaca en esta sentencia la diversidad de denominaciones usadas para referirse, por lo menos en apariencia, a una misma técnica: comunicación previa, comunicación fehaciente, notificación fehaciente y declaración de inicio de actividad. Muestra ello de la confusión -también terminológica- que, a día de hoy, preside estos institutos.

\section{LA DESAPARICIÓN DE ILÍCITOS ADMINISTRATIVOS CO- MO CONSECUENCIA DE LA REFORMA DE CIERTOS RE- GÍMENES SANGIONADORES}

En este bloque de sentencias que estudiaremos, los Tribunales Superiores de Justicia han tenido la oportunidad de dilucidar acerca de si las reformas normativas acaecidas (a raíz de la transposición de la Directiva de Servicios), han supuesto la desaparición de ilícitos administrativos que en su momento determinaron la responsabilidad de ciertos sujetos basadas en la inexistencia de una preceptiva licencia. También, colateralmente, sobre si es aplicable el principio de retroactividad de la norma sancionadora más favorable a una resolución firme en vía administrativa -que aplicó entonces la disposición vigente-, si ésta se encuentra en fase de revisión jurisdiccional cuando se produce la modificación.

El Tribunal Superior de Justicia de Canarias ha resuelto, en múltiples ocasiones, sobre las consecuencias de la reforma del régimen sancionador en materia de ordenación del turismo en dicha autonomía como resultado de la entrada en vigor de la Ley 14/2009, de 30 de diciembre. Tomaremos como ejemplo la primera en el tiempo de estas decisiones, pues las que suceden se limitan a reproducir sus fundamentos jurídicos ${ }^{41}$.

\footnotetext{
${ }^{41}$ Sentencias del Tribunal Superior de Justicia de Canarias: sentencia núm. 188/2010, de 13 de octubre de 2010; sentencia núm. 259/2010, de 21 de octubre de 2010; sentencia núm. 190/2010, de 3 de diciembre de 2010; sentencia núm. 193/2010, de 7 de diciembre de 2010; sentencia núm. 2/2011, de 21 de enero de 2011; sentencia núm. 98/2011, de 10 de junio de 2011; sentencia 97/2011, de 21 de junio de 2011; sentencia 26/2012, de 23 de diciembre de 2011; sentencia núm. 99/2012, de 8 de mayo de 2012; sentencia núm. 120/2012, de 27 de julio de 2012; sentencia núm. 230/2012, de 27 de julio de 2012; sentencia núm. 233/2012, de 27 de julio de 2012; sentencia núm. 136/2012, de 5 de octubre de 2012; sentencia núm. 266/2010, de 9 de noviembre de 2012; sentencia núm. 6/2013, de 8 de febrero de 2013; sentencia núm. 15/2013, de 28 de febrero de 2013; sentencia núm., 22/2013, de 15 de marzo de 2013; sentencia núm. 25/2013, de 15 de marzo de 2013; sentencia núm. 24/2013, de 19 de marzo de 2013; sentencia núm. 286/2013, de 9 de julio de 2013.
} 
La sentencia del Tribunal Superior de Justicia de Canarias núm. 184/2010, de 13 de octubre, resuelve un recurso presentado por la entidad mercantil Suite Taurito S.A. contra la desestimación del recurso de reposición interpuesto a la Orden del Consejero de Turismo del Gobierno de Canarias por la que se le imponía una sanción de 90.151 euros por la comisión de una infracción administrativa tipificada en la Ley 7/1995, de 6 de abril, de Ordenación del Turismo de Canarias. En concreto, por estar abierto al público un establecimiento hotelero sin la preceptiva autorización para la entrada en servicio y el desempeño de la actividad.

El órgano judicial entendió que lo relevante en aquel caso no era detenerse en si la sanción impuesta por la Administración había sido o no correcta conforme los hechos y el marco normativo vigente; ni tan siquiera si la desestimación del recurso contencioso ante el Tribunal de instancia fue acertada. El Tribunal Superior planteó a las partes -por vía del artículo 65.2 de la Ley de la jurisdicción contenciosa, como motivo relevante para el fallo distinto de los alegados en el proceso-, el alcance del principio de retroactividad de la ley sancionadora más favorable; y, en particular, la posible aplicación del mismo a la declaración de responsabilidad por la comisión de una infracción muy grave tipificada en la Ley de Ordenación del Turismo (tras la reforma del régimen sancionador obrada por la Ley canaria 14/2009, de 30 de diciembre).

El órgano jurisdiccional comienza por analizar si cabía entender que la referida reforma había hecho desaparecer el ilícito administrativo en base al cual la responsabilidad de la entidad mercantil había sido dictaminada.

En primer lugar, repasando brevemente el proceso de transposición de la Directiva de Servicios, constató el carácter excepcional del régimen autorizatorio para determinadas actividades. Recuerda que la ley estatal ni incide, ni puede hacerlo, en la potestad de la Comunidad Autónoma de regular, en el marco de la Directiva y la legislación básica que la incorpora al Ordenamiento, el ejercicio de materias exclusivas como el Turismo. Potestad que dio lugar, en el caso concreto, a la Ley a la que nos hemos referido; que generalizó el régimen de comunicación previa y declaración responsable para el inicio de actividades turísticas (reservando la exigencia de autorización a supuestos muy concretos).

Consideró el Tribunal que, con la nueva regulación, había desaparecido del catálogo de infracciones la del ejercicio de la actividad turística sin las autorizaciones preceptivas, por cuanto el nuevo régimen exige tan sólo la presentación de una declaración responsable. 
Así, en un ordenado y sencillo ejercicio deductivo, aseveró que "en tanto en cuanto que ha desaparecido la autorización previa, salvo en aquellos casos en que fuere preceptiva que no podrán ser determinados a priori, deja de existir la infracción que tipificaba, como infracción muy grave, la apertura de establecimientos sin dicha autorización en la que el reproche de la conducta venía determinado por ese ejercicio de la actividad si el control preventivo (...) por lo que podemos concluir que la conducta objeto de sanción, tal y como estaba descrita, ha dejado de ser típicamente antijurídica al regir el principio de libertad de establecimiento, sin necesidad de autorización previa, sin perjuicio del cumplimiento de los requisitos de comunicación y declaración responsable"42.

Después confirmar que la evolución sobrevenida del Ordenamiento jurídico había conllevado que la conducta por la que fue castigado el actor dejara de estar tipificada como infracción administrativa (por "dejar de merecer un juicio de desvalor para el legislador"43), se planteó el Tribunal la posibilidad de aplicación de principio de retroactividad de la norma sancionadora más favorable.

Tras una extensa cita de resoluciones del Tribunal Supremo concluyó que "en lo que respecta al ámbito administrativo sancionador no ofrece duda alguna la aplicación del principio de retroactividad de la norma sancionadora más favorable en el ámbito administrativo, en la instancia o en la vía de recurso aunque la infracción se haya cometido bajo la vigencia de la ley menos favorable, pero se proclama con rotundidad por el Alto Tribunal que también es aplicable en el ámbito del proceso, cuando la ley más favorable adquiere vigencia estando en fase judicial el examen de la legalidad de la declaración de responsabilidad y sanción impuesta en base a una normativa derogada, esto es, cuando el destinatario de la infracción ha adquirido ya la condición de sancionado por la resolución administrativa firme"44. De este modo, el TSJ de Canarias anula directamente la resolución recurrida ${ }^{45}$.

En este mismo apartado consideramos interesante mencionar la sentencia del Tribunal Superior de Justicia de Cataluña, núm. 888/2011, de 22 de diciembre. Supermercados Boya S.L y Budigues Aran, S.L presentaron recurso contencio-

${ }^{42}$ Fundamento jurídico tercero.

${ }^{43}$ Fundamento jurídico cuarto.

${ }^{44}$ Fundamento jurídico cuarto.

${ }^{45}$ De todas las sentencias de este Tribunal que resuelven sobre casos similares, baste destacar un par de ellas, que aun reproduciendo con exactitud los fundamentos jurídicos de la que acabamos de comentar, contienen alguna pincelada sobre otros temas conexos e igualmente interesantes.

Este es el caso, en primer lugar, de la STSJ de Canarias núm. 99/2012, de 8 de mayo de 2012. 
so-administrativo contra el Acuerdo del Gobierno de la Generalitat por el que se desestimaba el recurso de reposición contra el previo acuerdo que imponía, a las dos entidades mercantiles, una sanción de 300.501 euros por infracción de la normativa relativa a equipamientos Comerciales. En concreto, por abrir el establecimiento comercial sin la correspondiente licencia comercial autonómica exigida por la Ley 18/2005, de equipamientos comerciales.

La parte demandante consideró que la exigencia de licencia comercial para la apertura de establecimientos había sido eliminada por la aplicación directa de la Directiva 2006/123/CE -a pesar de no haber sido aún transpuesta, en aquel momento, al Derecho interno-, y que por lo tanto había dejado de existir tal infracción.

El Tribunal Superior resolvió rápidamente esta cuestión aduciendo que la tesis de la parte actora -de que la aplicación de la Directiva de servicios no permitía exigir ya licencia comercial-, no tenía sustento alguno, rechazando que la aplicación directa de la misma supusiera la eliminación de la licencia comercial; citando al respecto su compatibilidad con el artículo 43 del Tratado de Roma -garante de la libertad de establecimiento- declarada por sentencia del Tribunal de Justicia de 24 de marzo de 2011 (asunto C-400/2008).

En ella la entidad Surfing Club Aguila Playa impugna una previa sentencia del Juzgado de lo Contencioso administrativo alegando, entre otros, la falta de proporcionalidad de la sanción impuesta. Aunque finalmente declara ajustada a Derecho la cantidad de la multa fijada, realiza el Tribunal un interesante comentario acerca de los límites de actuación de la jurisdicción contenciosa: "respecto la vulneración del principio de proporcionalidad, la Jurisprudencia ha señalado (STS de 23 de enero de 1989, 3 de abril de 1990, 11 de junio de 1992, entre otras), que resulta posible al Tribunal no sólo la confirmación o eliminación de la sanción impuesta, sino su modificación o la reducción de su cuantía, respetando siempre las exigencias derivadas del principio "non reformatio in peius", en atención al control de proporcionalidad, esto es, a la debida adecuación entre gravedad del hecho constitutivo de infracción y la sanción aplicada, para el que han de tenerse en cuenta los criterios establecidos en el art. 131.3 de la LRJAP y PAC o los que especialmente se establezcan en el ordenamiento sectorial". Fundamento jurídico tercero.

En segundo lugar, el mismo Tribunal en sentencia núm. 136/2012, de 5 de octubre de 2012, anula una resolución sancionadora de la Administración y condena a ésta en costas a la cifra máxima de 1000 euros "dada la reiteración de asuntos". La justificación de esta condena en costas es la siguiente "la persistencia de la Administración tanto en la imposición de la sanción que nos ocupa como en la defensa en juicio de su posición, una vez que tenía conocimiento de la doctrina reiterada de esta Sala al respecto, le hace acreedora de la condena en costas por haber litigado con temeridad de acuerdo con lo dispuesto en el artículo 139.1 de la Ley reguladora de esta jurisdicción”. Fundamento jurídico tercero. 
El órgano jurisdiccional recordó a las partes, sin embargo, que ya en el momento en que se dictó el acto impugnado se encontraba en vigor la normativa de transposición de la Directiva en ese ámbito: el Decreto Ley 1/2009, de 22 de diciembre, de ordenación de equipamientos Comerciales; disposición que habría derogado la Ley 18/2005 en la que se basó la sanción recurrida. La nueva reglamentación diferenciaba los establecimientos que requieren comunicación previa o declaración responsable de los que continúan sometidos a autorización administrativa; siendo el caso de los establecimientos demandantes (por sus particularidades) susceptibles de someterse a cualquiera de los dos grupos de técnicas.

El Tribunal concluyó que, con independencia del cual fuere el régimen de intervención a que estuviera sometido el centro en la actualidad, la infracción por incumplirlo habría pasado de ser una infracción muy grave -en la Ley de 2005a tipificarse como grave -en el Decreto Ley de 2009-, con la consiguiente reducción de la sanción. "El artículo 128.2 LRJPAC obliga a aplicar la norma posterior más favorable al presunto infractor, incluso aunque su entrada en vigor se produzca después de firme y ejecutada la sanción administrativa; cuanto más si la entrada en vigor se produjo después de los hechos denunciados pero antes de dictarse la resolución administrativa impugnada"46.

Del conjunto de sentencias del Tribunal Superior de Justicia de Canarias, además de la ya evidente desaparición de ilícitos administrativos y sus sanciones asociadas, llaman la atención dos aspectos.

El primero, la cantidad de actividades al margen de la legalidad existentes antes de la entrada en vigor de la nueva normativa. Ahora que deben someterse a comunicación previa o declaración responsable ¿serán también tantas las actividades ilegales? El coste temporal de los procedimientos autorizatorios ¿podía actuar como "incentivo" de actividades en la clandestinidad? Por otro lado, si antes se incumplía la legislación ¿se cumplirá ahora con mayor rigor que la presencia o los controles de la Administración se han aplazado?

El segundo es que nos hallamos ante sanciones económicas de montantes, por lo general, nada desdeñables; consecuencia de la comisión de infracciones tipificadas por el Ordenamiento y perseguidas por una Administración que, a pesar de un correcto uso de sus potestades de control y sanción, dejará de ingresar en sus arcas cantidades sustanciosas. Seis de las resoluciones analizadas anulan sanciones de 105.000 euros, seguidas de tres de 90.000 , dos de 70.000 y cinco de 60000 y el resto de multas oscilan entre los 13.000 y los 30.000 euros.

\footnotetext{
${ }^{46}$ Fundamento jurídico cuarto.
} 


\section{LA SUBSANAGIÓN DE LAS DECLARACIONES RESPONSA- BLES Y LAS CONSEGUENGIAS DE LA OMISIÓN DE DA- TOS DE GARÁCTER ESENGIAL}

En la sentencia núm. 1141/2013, de 10 de octubre de 2013, el Tribunal Superior de Justicia de Andalucía conoce de la apelación a una sentencia que había confirmado la resolución desestimatoria de un recurso de alzada frente a una decisión de la Consejería de Turismo, comercio y deporte de la Junta de Andalucía. En esa decisión se resolvía tener por no presentada una declaración responsable -imprescindible para la inscripción de un establecimiento en el Registro de Turismo de Andalucía- y se ordenaba el cese de la actividad.

Como perfectamente sintetiza el propio Tribunal, la cuestión litigiosa se centra en "la obligación de consignar en la declaración responsable el grupo y categoría en el que pretende clasificar el establecimiento, y en las consecuencias procedimentales que su omisión comporta”. En resumidas cuentas, los interesados habían presentado la declaración responsable necesaria para que el establecimiento turístico pudiera ser inscrito en el correspondiente registro autonómico, omitiendo, sin embargo, el dato de su clasificación. Así, la Administración andaluza rechazó (tras distintas peticiones de subsanación) la declaración presentada, obligando a éstos al cierre del establecimiento.

La sociedad limitada "Casas de la Sierra Subbética", parte apelante, basó su recurso en cinco motivos. El primero, en la vulneración del artículo 39 de la Ley 30/1992 y de varios principios inspiradores tanto de la Directiva de Servicios como del Derecho Administrativo español. El segundo, en la errónea consideración de lo que cabe entender por datos de carácter esencial omitidos en la declaración responsable; el tercero, en el incumplimiento por parte de la Administración del deber de efectuar la sub-clasificación del establecimiento turístico; el cuarto, en la estimación presunta de la solicitud de inscripción por concurrencia de silencio administrativo; el quinto, en la vulneración del principio de confianza legítima y finalmente el sexto, en la del principio de autonomía local.

El primer, segundo y cuarto motivo de impugnación son, sin duda, los más interesantes. Plantean, en términos generales y desde distintas perspectivas, cuestiones relativas a los efectos jurídicos de las manifestaciones tanto de la Administración como de los administrados en el contexto de actividades sometidas a declaración responsable.

La parte demandante alegó en primer término la dificultad de cumplimentar el requerimiento autonómico relativo a la clasificación de la actividad en alguna 
de las subcategorías previstas en el modelo de declaración responsable. Incidiendo, sobre todo, en la falta de auxilio y colaboración prescrita tanto en la Ley de procedimiento como en la propia Directiva, pese a sus reiteradas peticiones.

Siendo la Administración autonómica la competente para proceder a la inscripción solicitada, y no habiendo el interesado hecho uso del ofrecimiento de auxilio de ésta ${ }^{47}$, dictaminó Tribunal que no podía admitirse el argumento de la imposibilidad de cumplimentar la declaración responsable por falta de colaboración de la entidad competente.

De este primer motivo de impugnación pueden extraerse, por lo menos, dos grandes conclusiones. Una, la aplicabilidad del principio-derecho de subsanación y mejora de las solicitudes de los particulares, también al supuesto de declaraciones responsables ${ }^{48}$. Y dos, la importancia del deber de colaboración de la Administración con el administrado; en especial en ámbitos en los que, como el de implantación de actividades, ha aumentado exponencialmente la responsabilidad de los particulares sobre aquello de lo que informan a la Administración. Ligado a esto último, están también las consecuencias jurídicas de lo que puede entenderse como un "consejo informal" y un "ofrecimiento explícito y por escrito" de auxilio de la Administración hacia el interesado.

El segundo motivo de impugnación se centró en la divergencia de opiniones de lo que cabía entender por datos esenciales en la declaración. El Tribunal, tras un repaso a la normativa autonómica aplicable en materia de turismo, consideró que "el dato relativo a la clasificación del establecimiento era de obligada cum-

47 A través de los hechos probados llegamos a conocer que una vez presentada la declaración responsable, la Administración requirió a la entidad para que la subsanara. Que esta lo hizo en aquello relativo a la titularidad del inmueble y título para la explotación, pero no en lo referente a la clasificación del establecimiento, por lo que fue objeto de un nuevo requerimiento de subsanación. Este fue respondido con un escrito en el que la demandante informaba del tipo de establecimiento y solicitaba a la Administración su clasificación; dando origen al tercer requerimiento de subsanación y al ofrecimiento a la interesada de la posibilidad de atender a sus consultas. Esta posibilidad nunca fue utilizada por la mercantil, que en su lugar se dirigió a una oficina municipal. Esta sería la que le habría aconsejado dejar en blanco el casillero correspondiente a la categoría de establecimiento en la declaración para que fuera rellenado por la Delegación provincial.

48 En este caso particular, materializado -tal vez incluso excesivamente- en hasta tres requerimientos.

${ }^{49}$ Se cita un precepto del Decreto por el que se regula la organización y funcionamiento del Registro de Turismo de Andalucía que considera de carácter esencial, entre otros, aquella "omisión en cualquier dato, manifestación o documento incorporado a la declaración responsable que afecte a la clasificación de los establecimientos de alojamiento turístico en cuanto al tipo, grupo o categoría". 
plimentación por el interesado" y que tenía el carácter de esencial ${ }^{49}$. Y justificó esta afirmación con el posterior comportamiento de la Administración: su acción repetida de requerir la subsanación de la declaración al interesado y "el ofrecimiento de colaboración realizado a tal efecto".

Dio así por correcta la decisión de no tener por presentada la declaración anudando a dicho incumplimiento la consecuencia del cese del ejercicio de la actividad. Consecuencia que, prevista en el apartado 4 del artículo 71 bis de la Ley 30/1992, reiteraba la normativa autonómica turística al establecer que "la omisión de un dato esencial en la declaración responsable determina la imposibilidad del ejercicio de la actividad turística afectada desde el momento en que se tenga constancia de tales hechos, así como la obligación de la persona interesada de restituir la situación jurídica al momento previo al ejercicio de la actividad".

La conclusión a la que llegamos en este apartado es relevante. De entrada, que aquello que debe considerarse un dato esencial corresponde, en efecto, a la normativa sectorial determinarlo. No obstante, lo verdaderamente substancioso es que según lo que se desprende del caso y de las consideraciones del Tribunal, ante la omisión de un dato de esta naturaleza (esencial), desde un punto de vista procedimental, procedería requerir su cumplimentación. No cabría, pues, distinción entre un dato u omisión esencial y una que no lo es: en ambos casos, se dispondría de un plazo para subsanar ${ }^{50}$.

La tercera alegación es la relativa a la obtención por silencio administrativo de la inscripción en el registro autonómico por transcurso del plazo previsto en la Ley autonómica de Turismo.

Utiliza el Tribunal distintos argumentos para evidenciar la no aplicabilidad de

50 STSJ de Canarias núm. 142/2012, de 17 de octubre. En esta sentencia, los demandantes impugnan el Decreto 141/2009, de 10 de noviembre, por el que se aprueba el Reglamento por el que se regulan los procedimientos administrativos relativos a la ejecución y puesta en servicio de las instalaciones eléctricas en Canarias. El aspecto que nos interesa es el cuestionamiento que realizan los recurrentes de la compatibilidad de un precepto del Decreto con lo dispuesto por el artículo 71 de la Ley de procedimiento; artículo, como es sabido, dedicado a la subsanación y mejora de las solicitudes.

En concreto el precepto autonómico reproducía lo que establece el artículo 7 lbis, apartado 4, de la Ley 30/1992, relativo a la inexactitud falsedad u omisión de carácter esencial, en cualquier dato, manifestación o documento que se acompañe o incorpore a una declaración responsable o a una comunicación previa. Dado que este artículo del Decreto era una copia del mencionado artículo de la Ley modificado en su momento por la Ley 25/2009, el Tribunal determinó su adecuación a la legalidad sin otro comentario ni valoración a respecto. Ciertamente, el objeto del recurso no era la 
este instituto al caso enjuiciado. El primero de ellos tiene que ver con la fase del procedimiento en el que se pretende reivindicar su presencia. El precepto alegado por la parte va referido a la comprobación por la Administración autonómica de la adecuación de una declaración responsable a la normativa turística desde unos extremos y en una fase distinta y anterior (relacionada con la construcción y calificación del establecimiento ${ }^{51}$ ) a la de inscripción del establecimiento en el Registro de turismo ${ }^{52}$. Así, el Tribunal entiende que los preceptos alegados de la norma autonómica no son los aplicables al caso; y que en estos últimos "no se prevé un determinado plazo para llevar a cabo la inscripción, ni que su incumplimiento lleve aparejado la obtención por silencio del derecho a esa inscripción" $" 53$.

El segundo argumento del Tribunal para descartar el silencio administrativo se plantea a los "meros efectos dialécticos" y partiendo de la hipótesis de la

compatibilidad de los dos preceptos de la Ley de procedimiento administrativo común, por lo tanto, no cabía esperar del Superior de Justicia un pronunciamiento concreto sobre el mismo.

Consideramos interesante, sin embargo, observar esta cuestión desde un prisma general reflexivo. Hasta qué punto el propio artículo 71 bis es en sí mismo "inexacto". ¿Qué tipo de inexactitudes, falsedades u omisiones no quedan amparadas por el derecho que asiste a los interesados a la subsanación y mejora de los escritos que presentan ante la Administración? Por ahora no se cuenta con resoluciones judiciales que aborden este particular lo que no disminuye su relevancia dentro del "procedimiento" que inician las declaraciones responsables y las comunicaciones previas.

Esta es, sin duda, una de las cuestiones del régimen jurídico de estas dos figuras que mayor problemática teórica (o de definición) y potencial presentan. Y lo es por su compatibilidad con el derecho apuntado; por aplicarse indistintamente a las mismas sin, a nuestro modo de ver, suficiente justificación; y, sobre todo, por la reacción jurídica que prevé el Ordenamiento, directamente asociada a una consecuencia económica para el particular -como es la suspensión del ejercicio del derecho o actividad- o a un supuesto de responsabilidad penal, civil o administrativa.

${ }^{51}$ Según el Tribunal "a ello debe responderse en primer lugar que ese precepto y apartado se refieren a la comprobación por parte de la Administración autonómica de la adecuación de la declaración responsable a la normativa turística reguladora de la clasificación aplicable al establecimiento de alojamiento turístico sujeto a clasificación administrativa cuya construcción, ampliación o reforma se proyecta, previendo que transcurrido el plazo de un mes sin que la Consejería hubiera comunicado o notificado objeciones, se considerará conforme con el proyecto". Fundamento jurídico tercero. Desde nuestro punto de vista, este precepto al que alude el órgano judicial (y que no es el aplicable al caso), tampoco regula la aplicación del instituto jurídico del silencio administrativo. Lo que instaura es un régimen de declaración responsable sometida a veto de la Administración.

${ }^{52}$ Se desprende de los hechos que existían diversas declaraciones responsables relacionadas con materia la urbanística y de actividades respectivamente.

${ }^{53}$ Fundamento jurídico cuarto. 
posibilidad de aplicar la obligación de resolver de la Administración y la figura del silencio positivo a actuaciones sometidas al régimen de declaración responsable. ${ }^{54}$

La argumentación se relaciona y justifica jurisprudencialmente con, en cualquier caso, la iniciación del plazo para resolver.

"De acuerdo con estos razonamientos no puede entenderse producido, ni siquiera iniciado, el transcurso del plazo para que se considere acaecido el silencio administrativo, desde el momento en que la declaración responsable no estaba revestida de las formalidades exigidas para el reconocimiento del derecho, pues no estaba debidamente cumplimentada al omitir datos esenciales que debían estar incorporados a la misma respecto al grupo y categoría en el que pretende clasificar el establecimiento a efectos de su inscripción. Más si se tiene en cuenta que la actora fue reiteradamente requerida de subsanación de aquella omisión, pese a lo cual no la hizo efectiva" 55 .

Respecto la vulneración del principio de confianza legítima, comienza el Superior de Justicia citando jurisprudencia del Tribunal Supremo y del Tribunal de Justicia de las Comunidades europeas en la que se resume su contenido: no puede la autoridad pública "adoptar medidas que resulten contrarias a la esperanza inducida por la razonable estabilidad en las decisiones de aquélla, y en función de las cuales los particulares han adoptado determinadas decisiones".

La clave para no considerar vulnerado este principio en el caso enjuiciado sería la falta de competencia de la autoridad que habría generado tal expectativa. Como fue alegado por la parte recurrente, no fue la Administración autonómica

54 Cuando el Tribunal expone la imposible hipótesis de aplicación, a la declaración responsable, de la obligación de resolver, trata además escuetamente de justificarlo utilizando la previsión del 42.1 de la Ley de Procedimiento. Como sabemos este artículo exceptúa de la obligación de resolver a los procedimientos sometidos únicamente al deber de comunicación previa a la Administración. Y en la medida que el 71 bis distingue la comunicación previa de la declaración responsable, podría no entenderse aplicable a este último régimen la salvedad apuntada.

Que el órgano judicial plantee este argumento deja patente que las dudas acerca de la identidad de régimen jurídico entre una y otra figura traspasan lo estrictamente doctrinal. En otras palabras, las previsiones de la Ley de procedimiento son ambiguas. Si el legislador pretendía, en efecto, excluir la técnica del silencio del régimen de la declaración responsable, lo esperable hubiera sido incluir ésta entre los instrumentos exentos de la obligación de resolver.

${ }^{55}$ Fundamento jurídico cuarto. 
responsable de la inscripción la que aconsejó omitir el dato de la clasificación en la declaración responsable, sino la Administración municipal. Este dato sumado a la correcta actuación de la Administración competente prestándose a colaborar, requiriendo la subsanación y advirtiendo de las consecuencias de su incumplimiento, lleva al órgano judicial a desestimar este motivo.

Por último, el argumento de la vulneración del principio de autonomía local se basó en la desaparición de la licencia municipal de apertura y su sustitución por la inscripción -por parte de la Administración autonómica- de la declaración responsable. Contesta escuetamente e ello el Tribunal, que no era ya necesario contar con la autorización municipal; que la competencia autonómica en materia de turismo le venía dada por el Estatuto de Autonomía de Andalucía y que la sustitución del procedimiento de comunicación previa originariamente previsto por el trámite de declaración responsable, constituía una modificación procedimental, que no competencial, que en nada afectaba a la autonomía local invocada ${ }^{56}$.

\section{GONGLUSIONES}

Las conclusiones a las que se puede llegar en este estudio respecto las resoluciones de los Tribunales son -por la corta trayectoria temporal de la reforma del régimen de intervención- provisionales. Aun así, todo lo que manifiestan y, en igual medida, los aspectos jurídicos irresolutos que soslayan, permite hacer una composición de lugar de la contribución, hasta el momento, de la jurisdicción contencioso-administrativa a la construcción del régimen de control a posteriori. Porque la responsabilidad de perfilar el contorno de las instituciones de la comunicación previa y declaración responsable es, ciertamente, compartida.

En primer lugar puede decirse, en general, que el Tribunal Supremo se ha mostrado estricto ante la necesidad de motivar, de la debida forma, el mantenimiento de la técnica autorizatoria. En ausencia de disposición comunitaria prescriptiva de la misma, no ha bastado la mera proclamación de la "necesidad" de su conservación. Ha sido exigente con la justificación legal o reglamentaria de la existencia de una razón imperiosa de interés general.

Es de menester que, desde la entrada en vigor de la reforma, las normas se interpreten a la luz de la misma; y en ello ha puesto el acento, también, el Alto Tribunal. Puede afirmarse que se ha mostrado, con todo, proclive al cambio de eje

${ }^{56}$ Fundamento jurídico sexto. 
vertebrador que la misma ha conllevado; a pesar de no entrar en aspectos como, por ejemplo, la distinción entre la técnica de la comunicación y la declaración responsable -diferenciación que tampoco le ha sido, hasta ahora, rogada- sí las ha calificado como medidas adecuadas de simplificación, menos gravosas e incomodas para los particulares.

Algún Tribunal Superior de Justicia, de forma aislada ciertamente, se muestra reacio al cambio normativo instaurado. Se manifiesta abiertamente favorable al mantenimiento de la técnica autorizatoria; no sólo calificándola sin tapujos como el sistema más seguro y mejor de control, si no asumiendo la tarea de justificar la existencia de una razón imperiosa de interés general que no había desarrollado la norma objetada.

La mayoría de Superiores de Justicia, por fortuna, muestran una actitud opuesta. Puede que sus argumentaciones aporten poco a lo ya dicho por el Tribunal Supremo respecto la sustitución de un régimen por otro, y algunos de ellos desperdician oportunidades de aclarar cuestiones conexas de fondo; sin embargo, realizan ciertas matizaciones que no por pequeñas dejan de ser importantes y que marcan una tendencia. Nos referimos, por ejemplo, a las relativas al ámbito de aplicación de la comunicación y la declaración. Sobre todo las que advierten de la distinción entre licencia urbanística y de actividad (a efectos de su sustitución), y de aquello que constituye una actividad de servicios y lo que no.

En segundo lugar, un aspecto en el que sí han incidido de modo más directo los Tribunales autonómicos es en el alcance de las potestades administrativas ante actividades desarrolladas de forma clandestina. La clandestinidad viene dada, como sabemos, por el ejercicio de actividades sin la precedente y preceptiva licencia o comunicación previa y declaración responsable. La reacción jurídica prevista por nuestro Ordenamiento ante tal eventualidad es la del cese de la actividad.

Lo dicho en este particular por los órganos del contencioso-administrativo puede resumirse de la siguiente forma: en primer lugar, la ausencia de licencia previa deslegitima por completo al interesado que pretenda instar la suspensión de una orden de clausura.

Los argumentos utilizados por los Tribunales como justificación a este hecho, podrían entenderse trasladables al supuesto de comunicaciones y declaraciones. Si bien es cierto que las actividades sometidas a estas técnicas obtienen la legitimación para su ejercicio ex lege, el requisito de su previa presentación ante la Administración deviene insoslayable. La actividad iniciada sin ella lo será en la clandestinidad; y en tanto que en la órbita de la ilegalidad, no debería de igual for- 
ma ser merecedora del privilegio de la suspensión.

En tercer lugar, el reconocimiento del derecho del interesado a la audiencia previa a la orden de cese es otra de las aportaciones de la jurisprudencia que merecen destacarse en este trabajo. Pese a una inicial manifestación contraria al mismo, queda clara la presencia de este trámite antes de la adopción de la medida cautelar de clausura de la actividad.

Constituye también, en cuarto lugar, una contribución al esclarecimiento del régimen jurídico de la comunicación y declaración responsable la nítida separación que marcan los órganos judiciales entre las actividades susceptibles de "legalizarse" y las que no.

Los requerimientos de legalización proceden en el contexto de implantación de usos urbanísticos. Cuando se trata de un supuesto de actividad ejercida sin la preceptiva comunicación o declaración sólo la audiencia al interesado constituye un derecho, sin que sean (por lo que se desprende de las resoluciones estudiadas) aplicables los procedimientos de restauración de la legalidad en dicho ámbito.

En quinto lugar, y directamente relacionado con el tema de las actividades clandestinas, el cambio de paradigma interventor despliega también sus efectos sobre el ejercicio de la potestad sancionadora de la Administración. La no sumisión de las actividades de servicios a autorización administrativa no solo impulsa las necesarias modificaciones legales o reglamentarias. Sus consecuencias impactan de lleno, además, sobre los actos administrativos firmes, fruto de procedimientos tramitados conforme la normativa vigente y con todas las garantías para los administrados.

La desaparición de ilícitos administrativos, como es el caso del ejercicio de una actividad sin la oportuna licencia, deriva de la aplicación del principio de retroactividad de las disposiciones más favorables para el interesado. Plantea, no obstante, no pocas cuestiones. Unas relacionadas con la desaparición de la antijuridicidad de la conducta y su justificación por los Tribunales; otras, con el alcance y los límites de actuación de la jurisdicción contencioso-administrativa.

Tal vez debiera matizarse, por un lado, la afirmación de la desaparición de la "conducta reprochable" que justifica la anulación de las sanciones ya impuestas. Desde nuestro punto de vista, la conducta del particular no ha dejado de ser, en sí misma, reprochable; puesto que hoy la no presentación de una comunicación previa o una declaración responsable lleva igualmente aparejada una sanción económica. Dicho de otro modo, el inicio de una actividad sin someterse a la legalidad vigente no ha dejado de ser ni jurídica ni socialmente censurable. El requisito de la comunicación a la Administración es expreso e ineludible. El no cumplimiento 
del mismo sitúa a los administrados al margen de lo lícito. Comunicación y declaración sustituyen a la autorización administrativa a todos los efectos; y su ausencia, en un caso como el otro, se castiga por el mismo fundamento.

Por otro lado, las resoluciones de los Tribunales de anulación de las sanciones administrativas plantean, como decíamos, dudas sobre el alcance de las decisiones de los mismos. Es tan evidente, en nuestra opinión, la desaparición del ilícito de ejercicio de actividad sin licencia, como lo es la antijuridicidad de la conducta de aquél que inicia una actividad sin la preceptiva presentación de una comunicación previa o declaración responsable.

La dudas que se plantean son varias. En primer lugar, si son competentes o no los órganos judiciales para sancionar, seguidamente, por la no presentación de la comunicación o declaración prevista -que no ha existido porque al tiempo del inicio empresarial no era el régimen vigente-. En segundo lugar, si debe ser la Administración la que instruya un nuevo expediente sancionador por el inicio de una actividad sin presentación de comunicación o declaración -cuando por el mismo razonamiento, al tiempo en que fue iniciada no era igualmente la técnica prevista-. En tercer lugar, si lo procedente es que el interesado presente, tras la anulación de la sanción, una comunicación o una declaración; "legalizando" así su actividad y habiendo sorteado (no sin cierta burla del sistema), la sanción por no presentación de autorización ni de cualquiera de estas dos técnicas.

En último lugar, el derecho de subsanación de la declaración responsable que contiene un error u omisión considerado esencial, se reconoce en la sentencia que cierra este estudio. Podemos afirmar sin vacilación alguna que ésta es una de las más relevantes contribuciones de la jurisprudencia al régimen jurídico de las instituciones estudiadas.

Este reconocimiento podría facilitar el encaje, sin complicaciones, del apartado 4 del 71 bis de la Ley 30/1992 en nuestro sistema de garantías procedimentales. La aludida imposibilidad de continuar con el ejercicio del derecho o actividad en estos casos desde el momento en que se tenga constancia de tales hechos lo sería, según la interpretación del Tribunal, tras la desatención del requerimiento de subsanación. Por lo tanto, quedaría garantizada la intervención previa del particular a la clausura del establecimiento y el debate en torno a la existencia o no de una previa audiencia del interesado a la adopción ipso facto de la medida de cierre perdería, desde este punto de vista, un poco de peso.

Entendemos, sin embargo, que pretender instaurar el derecho de subsanación de una declaración responsable por un dato que siendo esencial se omite, vacía o 
deja sin sentido la propia distinción que, implícitamente enunciada, instaura la Ley entre lo que son datos u omisiones esenciales y los que no lo son. Se anudan las mismas consecuencias jurídicas a unos y otros: la posibilidad de subsanación y, en su defecto, el cierre del establecimiento.

Queda así desvirtuada por completo la inmediatez en la adopción de la medida cautelar de cese para omisiones esenciales; incuestionable -al margen de las casi resueltas dudas sobre el presencia del trámite de audiencia- en la redacción literal del 71 bis de la Ley 30/92 y en las normas que sectorialmente lo reproducen.

La clave está, entendemos, en aquello que el legislador autonómico o sectorial considere un dato u omisión de carácter esencial. Porque es esta una medida que tiene (o debería tener) por finalidad la actuación rápida frente a una situación que pueda, efectivamente, generar algún tipo de riesgo. Por ello no sólo requiere que se especifique en cada norma si no que debería reservarse para omisiones u errores en verdad susceptibles de causarlo. De no ser así, podemos encontrarnos con que la medida de cierre no resulte ser proporcionada a la gravedad de las circunstancias concurrentes, debido a una mala configuración legal de lo que cabe entender por esencial. 